\title{
A20 as an immune tolerance factor can determine islet transplant outcomes
}

\author{
Nathan W. Zammit,, Stacey N. Walters, ${ }^{1}$ Karen L. Seeberger, ${ }^{2}$ Philip J. O'Connell, ${ }^{3}$ \\ Gregory S. Korbutt, ${ }^{2}$ and Shane T. Grey' \\ ${ }^{1}$ Immunology Department, Garvan Institute of Medical Research, Darlinghurst, New South Wales, Australia. ${ }^{2}$ Department \\ of Surgery, University of Alberta, Edmonton, Alberta, Canada. ${ }^{3}$ Centre for Transplant and Renal Research, Westmead \\ Institute for Medical Research, University of Sydney at Westmead Hospital, NSW Australia.
}

Islet transplantation can restore lost glycemic control in type 1 diabetes subjects but is restricted in its clinical application by a limiting supply of islets and the need for heavy immune suppression to prevent rejection. TNFAIP3, encoding the ubiquitin editing enzyme A20, regulates the activation of immune cells by raising NF- $\kappa B$ signaling thresholds. Here, we show that increasing A20 expression in allogeneic islet grafts resulted in permanent survival for $\sim 45 \%$ of recipients, and > $80 \%$ survival when combined with subtherapeutic rapamycin. Allograft survival was dependent upon Tregs and was antigen specific, and grafts showed reduced expression of inflammatory factors. Transplantation of islets with A20 containing a loss-of-function variant (I325N) resulted in increased RIPK1 ubiquitination and NF-кB signaling, graft hyperinflammation, and acute allograft rejection. Overexpression of A20 in human islets potently reduced expression of inflammatory mediators, with no impact on glucose-stimulated insulin secretion. Therapeutic administration of A20 raises inflammatory signaling thresholds to favor immune tolerance and promotes islet allogeneic survival. Clinically, this would allow for reduced immunosuppression and support the use of alternate islet sources.

Conflict of interest: The authors have declared that no conflict of interest exists.

Copyright: (c) 2019, American Society for Clinical Investigation.

Submitted: June 12, 2019

Accepted: September 25, 2019

Published: November 1, 2019.

Reference information: /CI Insight. 2019:4(21):e131028.

https://doi.org/10.1172/jici.

insight.131028.

\section{Introduction}

Type 1 diabetes (T1D) is an autoimmune condition marked by loss of glycemic control caused by immune-mediated destruction of insulin producing $\beta$ cells that reside within the pancreatic islets of Langerhans (1). Replacement of lost $\beta$ cells by adult islet allogeneic transplantation restores glycemic control, providing fine-tuned release of insulin in response to blood glucose in real time, something not yet achievable by manual or automatic injection of insulin or its analogues (2-4). Islet transplantation reduces exogenous insulin requirements and reverses hypo-]glycemic unawareness, a life-threatening complication of T1D $(3,5,6)$. Although highly successful, the need for robust suppression of host immunity to avoid rejection precludes its indication for pediatric T1D patients, restricting the broader application of islet transplantation to adults with life-threatening hypoglycemic unawareness $(2,7)$.

Islet transplantation is further restricted by the scarcity and fragility of islets. Frequently, patients require multiple islet infusions extracted from multiple pancreata to achieve clinical outcomes of insulin independence and reversal of hypoglycemic unawareness $(4,6,8)$. Further, most islet transplant recipients show relatively poor long-term outcomes compared with solid organ transplant recipients, requiring a return to insulin injections within a few years after islet transplant $(2,4)$. Evidence suggests the underlying mechanisms leading to reduced islet allograft survival are unique to islet transplantation and include recurrent islet autoimmunity, sensitivity of islets to the intraportal transplant site, and islet toxicity of immunosuppressive drugs, as well as factors present in solid organ transplantation, such as chronic allograft rejection (2). These factors are likely exacerbated by autologous islet inflammation induced via the isolation process and ex vivo culture that may hasten graft failure and increase their immunogenicity after transplant (9-12). Strategies that reduce islet fragility and inflammation could preserve islet graft mass and improve posttransplant function, potentially reducing the reliance on heavy immunosuppression and widening the eligibility criteria for an islet transplant (10).

TNFAIP3, encoding the ubiquitin editing protein $\mathrm{A} 20$, is a master regulator of $\mathrm{NF}-\kappa \mathrm{B}$ signaling. A20, through its ovarian tumor (OTU) and zinc finger 4 domain, modifies ubiquitin chains on key intracellular 
inflammatory signaling mediators, primarily RIPK1 (receptor-interacting serine/threonine-protein kinase 1) and TRAF6 $(13,14)$, that lie downstream of inflammatory and danger-sensing receptors of the TNF receptor family, including TNFR1, IL-1R, and TLRs. In hematopoietic cells, A20 functions as a negative regulator of immunostimulatory factors and, thus, governs the threshold for immune activation. Reduced expression of A20 in DCs leads to increased expression of costimulatory molecules and an enhanced ability to activate $\mathrm{CD}^{+}$and $\mathrm{CD}^{+} \mathrm{T}$ cells during an immune response (15-17). Further, deletion of A20 in B cells, macrophages, and granulocytes results in cell intrinsic hyperactivation and spontaneous inflammatory disease in mice (18-21). In human subjects, A20 haploinsufficiency is associated with increased serum cytokines, higher frequencies of TH17 cells, and autoimmune disease $(22,23)$. Thus, by regulating NF- $\mathrm{BB}$ activation, A20 sets the threshold for the generation of a productive immune response. Here, we investigated the impact of changed A20 expression levels in islet allografts on immunostimulatory thresholds and islet allograft survival.

\section{Results}

Forced expression of A20 allows permanent islet allograft survival without the necessity of immunosuppression. Transduction of an islet cell line with an adenoviral vector encoding human A20 (recombinant adenovirus A20; rAd.A20) to force A20 expression to high levels suppressed TNF-induced NF- $\mathrm{BB}$ and JNK signaling pathways, inhibited activation of a NF- $\mathrm{KB}$ and an AP-1 reporter, and suppressed expression of proinflammatory factors associated with allograft rejection (Figure 1, A-E, Supplemental Figure 1, A and B, and ref. 9; supplemental material available online with this article; https://doi.org/10.1172/jci.insight.131028DS1). Forced expression of A20 in primary mouse islets resulted in suppression of TNF-induced proinflammatory genes as compared with control islets transduced with rAd.GFP (GFP-expressing) or left noninfected (NI) (Figure 2, A and B, and Supplemental Figure 1C). To test the impact of A20 on tissue tolerance to transplanted islets, primary NI islets from BALB/c $\left(\mathrm{H}_{2}^{\mathrm{d}}\right)$ donor mice, or islets transduced with rAd.A20 or $\mathrm{rAd}$. GFP were transplanted into diabetic C57BL/6 $\left(\mathrm{H}^{\mathrm{b}}\right)$ allogeneic recipients. Adenoviral transduction did not affect islet graft function in vivo, as demonstrated by the ability of rAd.A20, control rAd.GFP, and NI grafts to rapidly restore euglycemia in the immediate posttransplantation period (Figure 2C). Kaplan-Meier survival analysis showed rapid rejection of control NI and rAd.GFP-transduced islet allografts. In contrast, $\sim 50 \%$ of mice receiving A20-expressing islets failed to reject their grafts and, instead, exhibited permanent $(>200$ days) allograft survival (Figure 2D). Graft removal by survival nephrectomy for some recipients at postoperative day (POD) 100 disrupted glucose control, illustrating that A20-transduced surviving islet grafts were both functional and responsible for euglycemia (Figure 2E). Long-term-surviving A20-transduced grafts were characterized by normal islet architecture, robust insulin production, and distinct pockets of mononuclear cells within the graft microenvironment (Figure 2F). Improved graft morphology was also evident for A20-expressing grafts at POD 10 (Figure 2G). A20-expressing grafts expressed reduced levels of inflammatory mRNAs such as Cxcl10, Icam1, and Ccl2 (Figure 2H and Supplemental Table 1). These same mRNAs were also reduced in long-term-surviving A20-expressing grafts (Figure 2H). Thus, forced expression of A20 allows permanent and functional survival of an islet allograft without needing immunosuppressive drugs.

Immune features of A20-induced islet allograft survival. We investigated the immunological mechanism for long-term survival of A20-expressing allografts. One hundred fifty days after transplantation, splenic T cells were harvested from mice with $\mathrm{A} 20$-expressing $\mathrm{BALB} / \mathrm{c}\left(\mathrm{H} 2^{\mathrm{d}}\right)$ islet grafts and were adoptively transferred to $\mathrm{RAG}^{-/-}$mice previously transplanted with a BALB/c $\left(\mathrm{H} 2^{\mathrm{d}}\right)$ islet allograft. Control groups received splenic $\mathrm{T}$ cells harvested from C57BL/6 mice (Figure 3A). In this situation, $\mathrm{RAG}^{-1-}$ mice receiving $\mathrm{T}$ cells taken from mice with surviving A20-expressing grafts took longer to reject their islet grafts and the majority permanently accepted the allograft, compared with $\mathrm{RAG}^{-/-}$mice receiving $\mathrm{T}$ cells from C57BL/6 mice (Figure 3B). Thus, A20-induced islet allograft acceptance is $\mathrm{T}$ cell dependent. To determine whether graft acceptance was due to T cell anergy, deletion, or regulation, we repeated the above experiment; however, this time, we transferred $\mathrm{T}$ cells depleted of $\mathrm{CD} 25^{+} \mathrm{T}$ cells from mice harboring long-term-surviving A20-expressing or -rejecting control NI islet grafts. These $\mathrm{T}$ cell preparations lacked $\mathrm{CD} 4{ }^{+} \mathrm{CD} 25^{+} \mathrm{T}$ cells with regulatory potential $(24,25)$. In this experiment, all of the recipient mice rejected the second BALB/c allograft, regardless of whether they received effector $\mathrm{T}$ cells from mice with A20-expressing grafts or control grafts (Figure $3 \mathrm{~B}$ ). This indicated to us that A20 expression engendered T cell dependent tolerance. To test if graft acceptance was specific to the BALB/c (H2 $)$ alloantigen, we established another cohort of long-term-surviving A20-expressing islet graft recipient mice to repeat the above experiment. However, in this case, the $\mathrm{T}$ cells from mice harboring A20-expressing long-term-surviving grafts were adoptively transferred into $\mathrm{RAG}^{-/-}$mice 

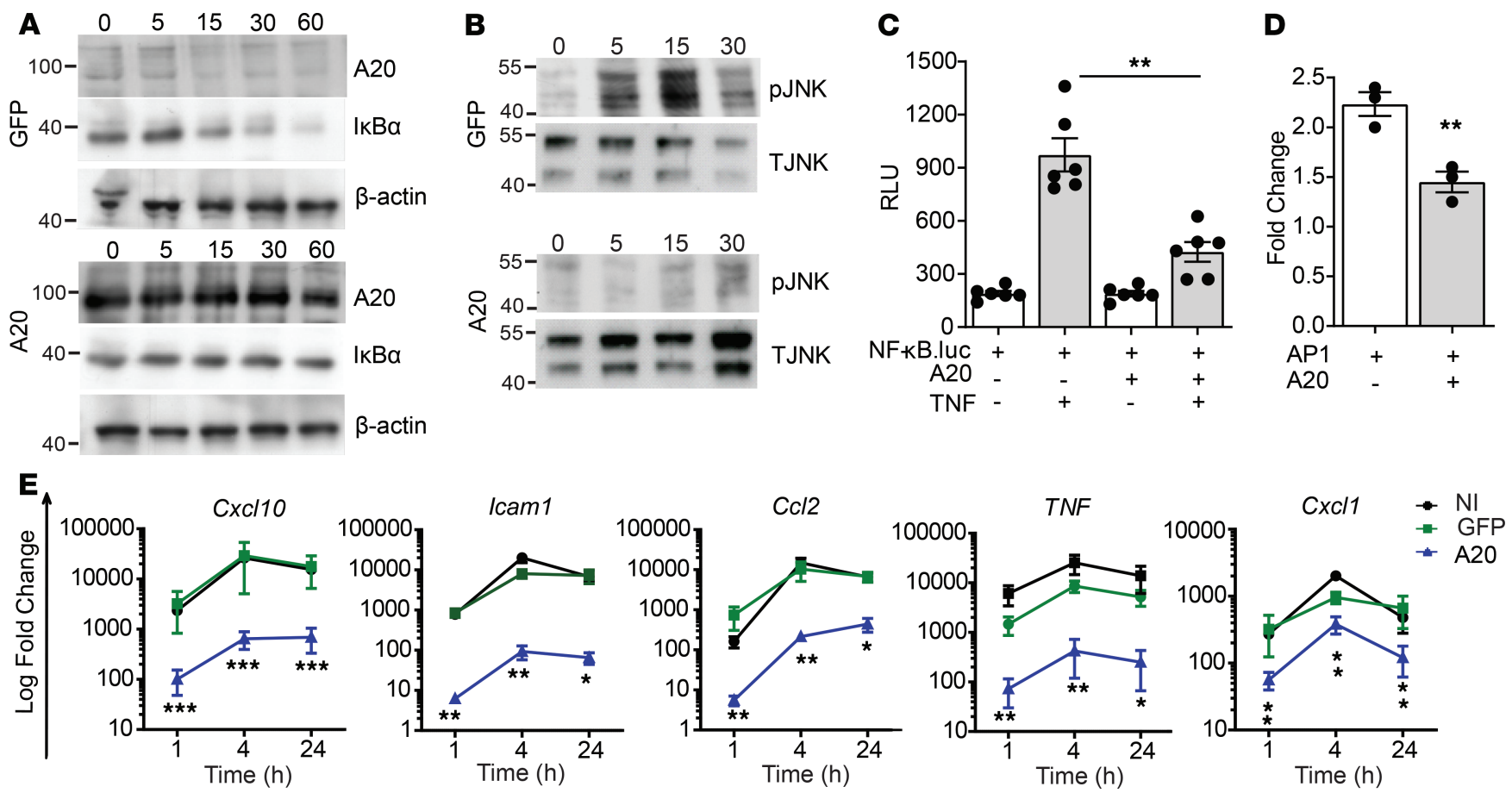

Figure 1. A20 inhibits TNF-induced inflammatory signaling in $\boldsymbol{\beta}$ cells. (A and B) Immunoblot of lysates from MIN6 $\beta$ cells transduced with recombinant adenovirus encoding GFP or human A20 (MOI 100:1) and stimulated with $200 \mathrm{U} / \mathrm{mL}$ TNF for the indicated times and probed with antibodies for A20, IKB $\alpha$, JNK (T JNK), phospho-JNK (pJNK), or $\beta$-actin (loading control). (C and D) $\beta$ TC3 cells cotransfected with a NF-kB.luciferase reporter (C) or an AP-1.luciferase reporter (D) and a CMV.ßgal expression construct \pm PCDNA3.1-encoding A20 and stimulated with $200 \mathrm{U} / \mathrm{mL}$ TNF for 8 hours or left untreated. RLU, relative light units (luciferase/ßgal). (E) Noninfected (NI) MIN6 cells, or GFP- or A20-transduced MIN6 cells, were treated for 1, 4, and 24 hours, and expression of induced genes were assessed. Error bars represent mean \pm SEM. Data represent 3 independent experiments, and statistical significance was determined by 1-way ANOVA with Tukey's multiple comparisons post hoc test (C and E) or 2-tailed Student's $t$ test (D). ${ }^{*} P<0.05 ;{ }^{* *} P<0.01 ;{ }^{* * *} P<0.001$.

pretransplanted with a MHC-disparate graft from a different $\left(\mathrm{H} 2^{k}\right)$ donor strain (Figure 3C). Subsequently, in all cases, the $\mathrm{H} 2^{\mathrm{k}}$ MHC-mismatched grafts were rapidly rejected. We conclude from these experiments that the major mechanism of tolerance induced by A20-intragraft expression is exerted by T cell-dependent and antigen-specific immune regulation toward the islet allograft. However, we cannot exclude other complementary mechanisms of tolerance, such as effector $\mathrm{T}$ cell deletion or $\mathrm{T}$ cell anergy.

Forced expression of A20 promotes the accumulation of intragraft Foxp $3^{+} T$ cells. Both A20- and GFP-expressing islet allografts were infiltrated with FOXP3 ${ }^{+} \mathrm{T}$ cells at POD 10 after transplantation (Figure 4A), but the number of FOXP3 ${ }^{+} \mathrm{T}$ cells within the GFP-graft microenvironment subsequently fell during the time period when grafts were being rejected between POD 15-25. In contrast, A20-expressing grafts maintained high numbers of FOXP3 $3^{+}$T cells (Figure 4, B-D). Also, long-term-surviving A20-expressing grafts (>100 days) showed prominent infiltration of $\mathrm{FOXP}^{+} \mathrm{T}$ cells congregated within the perigraft space appearing to surround each individual islet (Figure 4C). The presence of $\mathrm{FOXP}^{+} \mathrm{T}$ cells always correlated with improved islet graft architecture, whereas the immunopathology of rejecting grafts revealed reduced number of FOXP3 ${ }^{+} \mathrm{T}$ cells with fragmented, less defined islet architecture; patchy insulin labeling; and increased numbers of graft $\mathrm{CD} 4^{+}$and $\mathrm{CD}^{+} \mathrm{T}$ cells compared with A20-expressing grafts (Figure 4, A-C, and Supplemental Figure 2A). A20-expressing grafts at $\mathrm{POD} 10$, showed a reduced frequency of $\mathrm{CD} 8^{+}$and $\mathrm{CD} 4^{+} \mathrm{T}$ cells within the graft site compared with GFP-expressing grafts (Supplemental Figure 2, B and C). Increased FOXP3 ${ }^{+} \mathrm{T}$ cells and a reduced frequency of $\mathrm{CD} 8^{+}$and $\mathrm{CD} 4^{+} \mathrm{T}$ cells within the graft site was associated with elevated levels of $\mathrm{Tg} f b$ mRNA and a trend to increased levels of $I 110 \mathrm{mRNA}$ within the A20-expressing islet graft microenvironment (Figure 4, D and E, and Supplemental Figure 2D). Ccl22, a chemokine that attracts Tregs (26), was not found to be differentially expressed between groups. There was also no overall change in the level of DC activation markers $C d 80$ or $C d 86$ between A20- or GFP-expressing grafts at POD 10 (Figure 4E).

Within long-term-surviving grafts (>100 days), FOXP3 ${ }^{+} \mathrm{T}$ cells and high levels of Foxp 3 mRNA were readily detected (Figure $4, \mathrm{C}$ and $\mathrm{E}$ ). In addition, increased $\mathrm{CD} 4^{+} \mathrm{CD} 25^{+} \mathrm{FOXP} 3^{+} \mathrm{T}$ cells were also detected in the spleen and graft draining (renal) lymph node of mice harboring long-term-surviving 


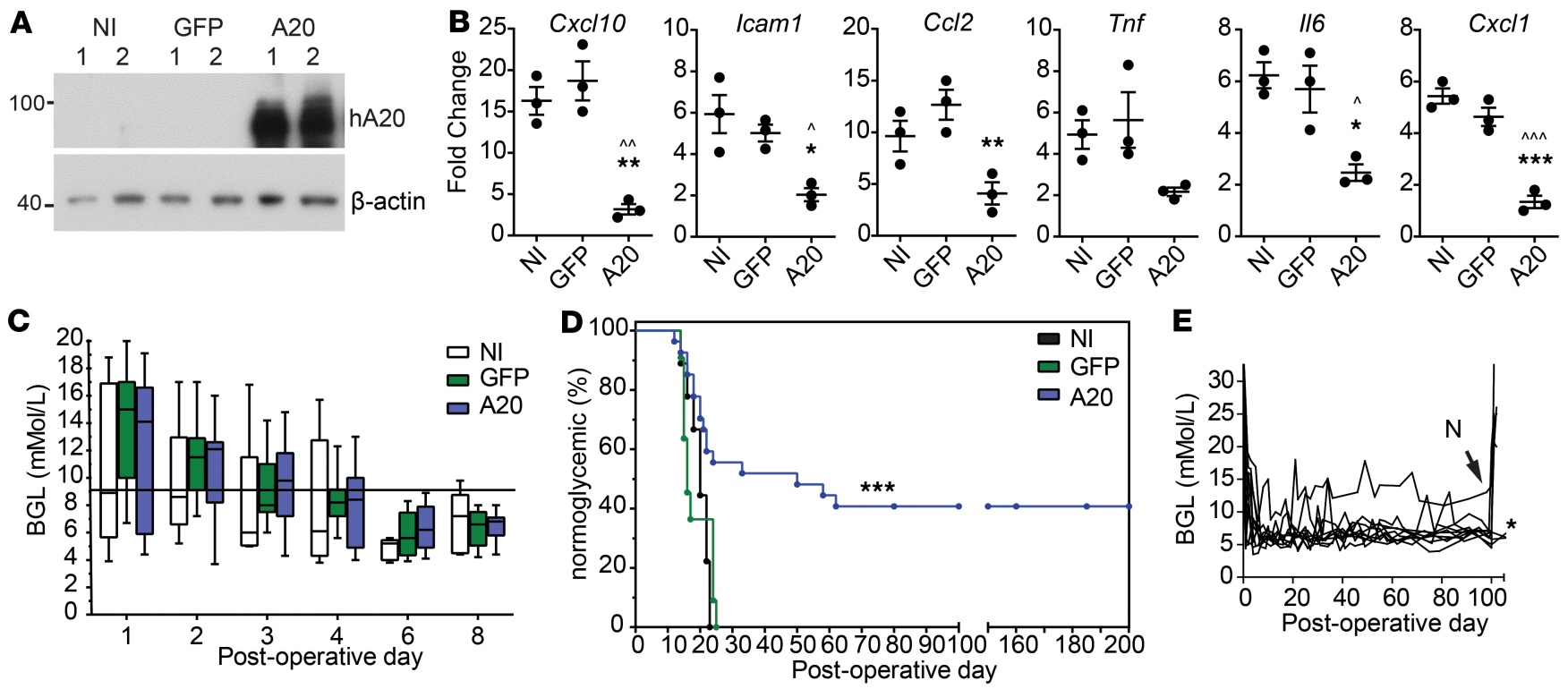

$\mathbf{F}$

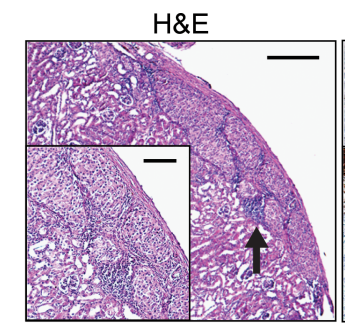

INS

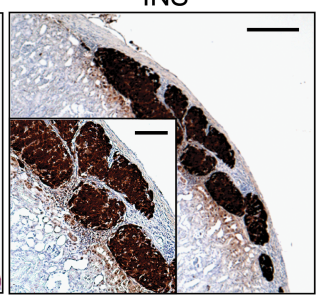

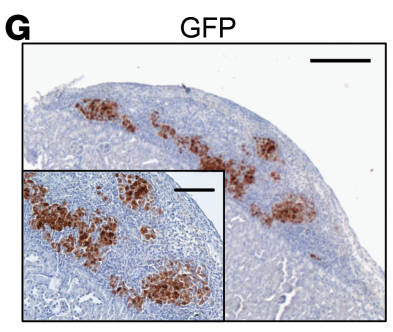

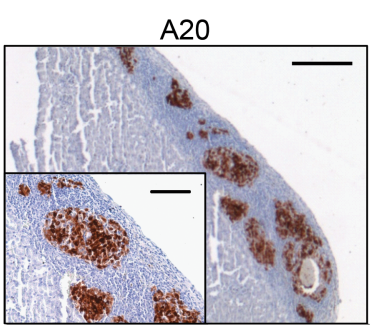

H
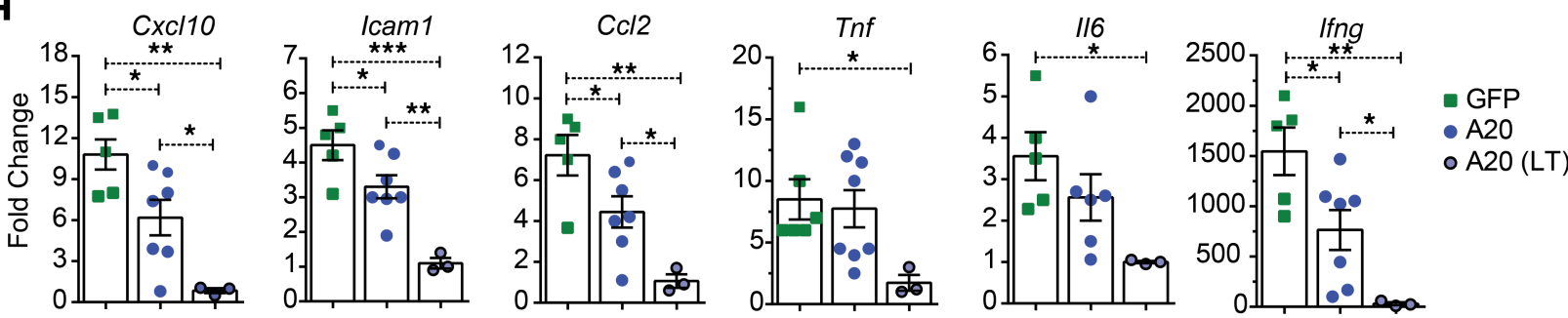

Figure 2. Improved survival characteristics of an A20-expressing islet allograft. Primary islet preparations transduced with adenoviral constructs encoding for GFP or human A20 or left noninfected (NI) were (A) lysed in duplicate (1 and 2), with A20 protein levels assessed by immunoblot, or (B) treated with 200 $\mathrm{U} / \mathrm{mL}$ of TNF for 4 hours and expression of inflammatory factors measured ( ${ }^{*}$ represents A2O versus GFP; ${ }^{\wedge}$ represents A20 versus NI). Data represent 3 independent islet preparations. ( $C$ and $\mathbf{D}) 300 \mathrm{NI}$ islets $(n=11)$ or those expressing GFP $(n=9 ; P=0.16)$ or $\mathrm{A} 20(n=27 ; P=0.002)$ were transplanted under the kidney capsule of allogeneic C57BL/6 mice and (C) blood glucose levels (BCL) and (D) percent of mice remaining normoglycemic monitored for the indicated days. Significance determined by Log-rank test. (E) Nephrectomies (N) were conducted at postoperative day (POD) 100 for a portion of A20-expressing long-term-surviving islet grafts. (F) H\&E staining or insulin labeling (INS) of long-term-surviving ( $>100$ days)grafts, representative of 7 long-term-surviving grafts. (C) Insulin staining of GFP- or A20-expressing grafts at POD 10. Scale bar: $200 \mu \mathrm{m}$ (4x magnification) and $100 \mu \mathrm{m}$ for panel inserts (10x magnification), representative of 4 islet grafts per treatment. (H) RNA levels of inflammatory factors from GFP- (closed square) or A20- (closed circle) expressing grafts harvested at POD 10, as well as A20-transduced long-term-surviving grafts harvested at > POD 100 (gray-filled circle). Each point in a column represents an individual islet graft. Nontransplanted overnight-cultured isolated islets were used as baseline. Error bars \pm SEM and statistical significance determined by 1-way ANOVA with Tukey's multiple comparisons post hoc test; ${ }^{*} P<0.05 ;{ }^{* *} P<0.01 ;{ }^{* * *} P<0.001 ;{ }^{\wedge} P<0.05 ;{ }^{\wedge \wedge} P<0.01 ;{ }^{\wedge \wedge} P<0.001$.

grafts (Figure 4F). Therefore, A20 alters the proinflammatory milieu, leading to the accumulation of Tregs within the graft microenvironment.

Reducing Tregs reverses A20-mediated graft survival. To further investigate the role of Tregs in A20-induced tolerance, we treated diabetic recipient mice with the $\alpha \mathrm{CD} 25 \mathrm{mAb}$ clone PC61, which depletes $\mathrm{CD}_{25}{ }^{+} \mathrm{FOXP}^{+}$Tregs (Supplemental Figure 3 and ref. 27) by preventing CD25 binding to IL-2 $(28,29)$. In this experiment, all of the mice receiving A20-transduced grafts and treated with PC61 mAb at the day of transplantation, and every 10 days thereafter, rapidly rejected their grafts with similar rejection times to those observed for control GFP-expressing grafts (Figure 5A). In contrast, $40 \%$ of recipients of A20-expressing grafts injected with an isotype control antibody exhibited long-term survival (Figure 5A). 
A

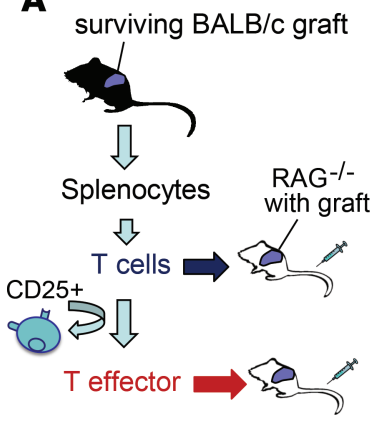

B

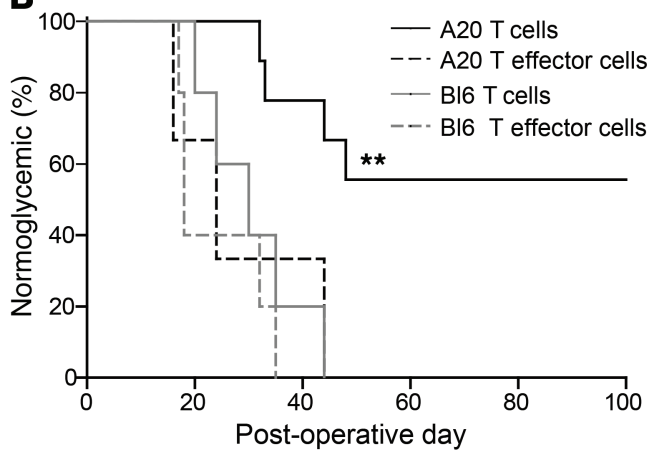

C

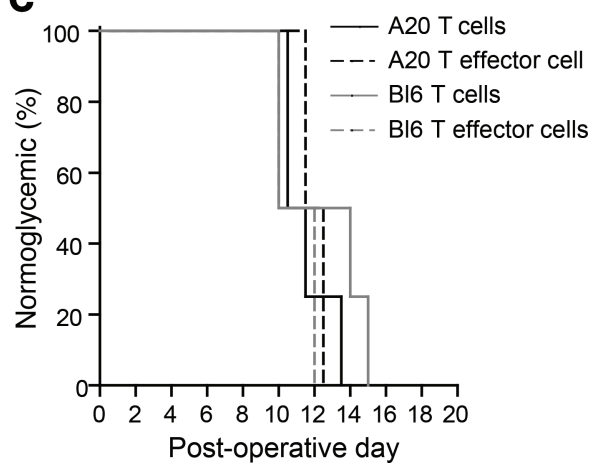

Figure 3. A20-induced islet allograft survival is T cell dependent and is antigen specific. (A) Experimental strategy. (B) Diabetic RAG ${ }^{-1-}$ mice pretransplanted with $300 \mathrm{BALB} / \mathrm{c}$ islets to restore euglycemia were adoptively transferred with T cells or CD25-depleted T effector cells, from mice harboring long-term-surviving grafts (A20 T cells, $n=9$; A20 T effector cells, $n=3$ ), or control C57BL/ 6 mice (BI6 T cells, $n=5$; BI6 T effector cells, $n$ = 5). Blood glucose levels were monitored and percent of mice remaining normoglycemic recorded as a read out of islet graft function. (C) Diabetic $\mathrm{RAC}^{-1-}$ mice were pretransplanted with 300 islets from third-party $\mathrm{CBA}\left(\mathrm{H} 2^{\mathrm{k}}\right)$ donors and adoptively transferred with $\mathrm{T}$ cells or CD25-depleted T effector cells from mice harboring long-term-surviving grafts (A20 T cell, $n=4$; A20 T effector cell, $n=2$ ) or control C57BL/6 grafts (BI6 T cell, $n=4$; BI6 T effector cell, $n=2$ ). Blood glucose levels were monitored and percent of mice remaining normoglycemic recorded as a read out of islet graft function. Significance determined by Log-rank test (B and $\mathbf{C}$ ); ${ }^{* *} P<0.01$.

We conclude that graft intrinsic expression of A20 can promote Treg-dependent tolerance to an MHC mismatched islet allograft.

Rapamycin (also known as sirolimus) inhibits mTOR and is used clinically as an immunosuppressant to dampen $\mathrm{T}$ cell responses in transplantation $(4,6)$. Preclinical and clinical studies also indicate that rapamycin promotes FOXP3 $3^{+}$Tregs (30-33); therefore, we investigated whether graft intrinsic expression of A20 would synergize with the tolerance-promoting properties of rapamycin. For the experiment, diabetic C57BL/6 recipients received A20-expressing $\mathrm{H} 2^{\mathrm{d}} \mathrm{BALB} / \mathrm{c}$ islet allografts, as well as 7 daily injections of a limiting subtherapeutic dose of rapamycin (34) starting on the day of transplantation (Figure 5B). All control GFP-expressing grafts, and those treated with rapamycin alone, were rapidly rejected, whereas mice receiving A20-expressing grafts and treated with a subtherapeutic dose of rapamycin showed superior graft survival compared with grafts transduced with A20 alone (Figure 5B). These data highlight the translational potential of A20 to synergize with clinical approaches that enhance Tregs and promote significant improvements in islet allograft outcomes.

A20 promotes tissue tolerance by regulating RIPK1. Since increasing intra-graft A20 levels can promote allograft tolerance by increasing the threshold for NF- $\mathrm{kB}$ activation, we investigated whether A20 reduction would have the reverse effect and promote inflammation with more aggressive allograft rejection. To test this, we utilized an $N$-ethyl- $N$-nitrosourea mutagenesis-generated (ENU mutagenesis-generated) mouse line harboring a germline A20 loss-of-function mutation $(35,36)$. This coding mutation lies within the functional OTU ubiquitin editing domain of A20 $(13,36)$ and substitutes a conserved isoleucine at amino acid position 325 for an asparagine (I325N). When transiently expressed, in pancreatic $\beta$ cell lines, that the I325N mutation impairs A20's ability to inhibit TNF-induced NF- $\mathrm{kB}$ and JNK reporter activation (Figure 6, A and B, and Supplemental Figure 4, A and B), and when overexpressed in WT mouse islets, the I325N A20 variant shows a reduced ability to inhibit TNF-induced inflammatory gene expression as compared with islet-expressing WT A20 (Figure 6C). A20 regulates inflammatory signaling by terminating RIPK1 activation via cleavage of K63 ubiquitin chains with its OTU domain and targeting substrates for K48-mediated proteosomal degradation via its zinc finger 4 ubiquitin ligase domain (13). The I325N mutation does not alter A20 protein stability, nor A20's capacity to interact with key substrates RIPK1 or NEMO in $\beta$ cells (Figure 6, D and E, and Supplemental Figure 4, C and D). Rather, the I325N mutation resulted in increased accumulation of RIPK1, consistent with a reduction in A20's ubiquitin editing function (13). Islets isolated from I325N mice exhibit increased TNF-induced gene expression compared with WT islets (Figure 6F). When transplanted into diabetic allogeneic recipients, I325N islets showed accelerated rejection and a hyperinflammatory graft microenvironment with heightened expression of Cxcl10, Ifng, and reduced expression of $T g f b$ (Figure 6, G-I). Thus, A20 is necessary to control islet homeostasis in response to inflammatory triggers. In the specific context of islet transplantation, changing A20 levels can function as an immune modulatory control switch that dictates islet transplant outcomes by regulating islet RIPK1 levels. 
A

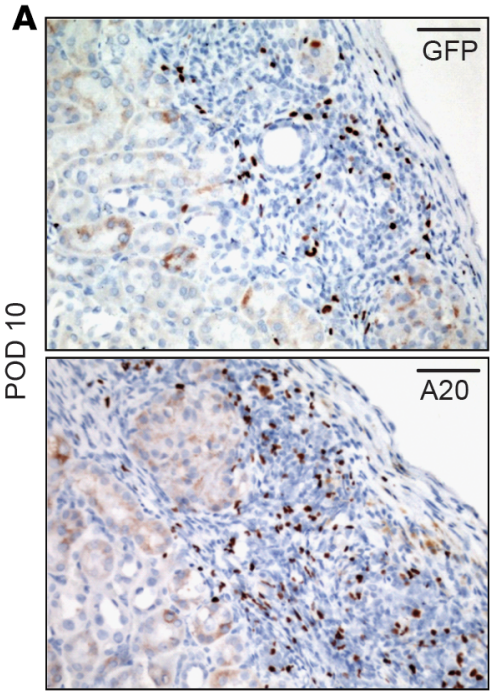

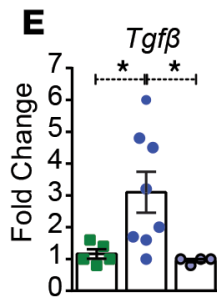

Ccl22

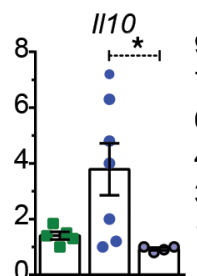

Cd3
B

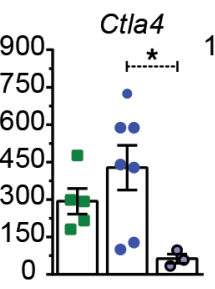

Cd80

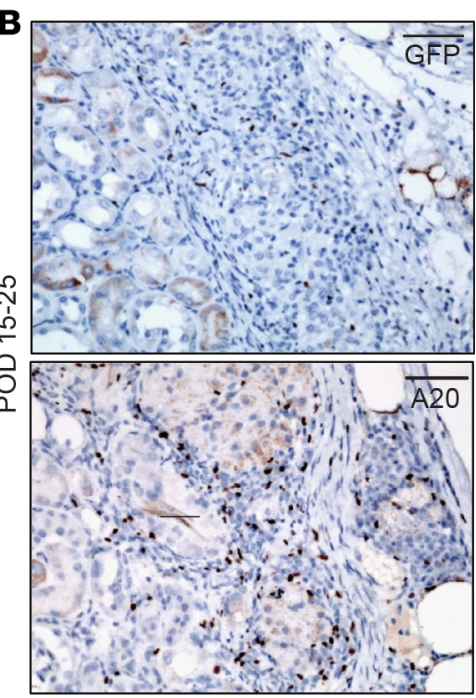

$\mathbf{F}$

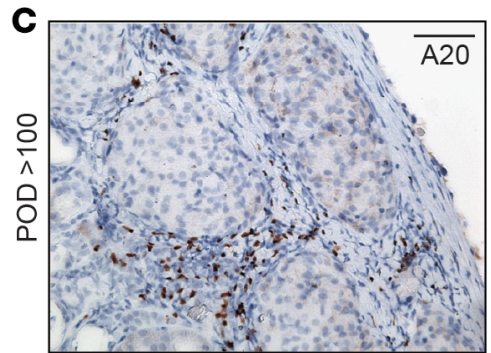

D 8

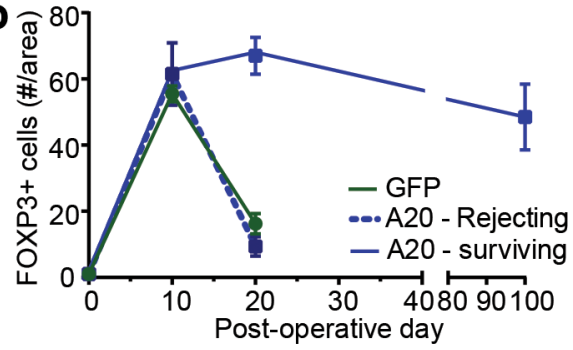

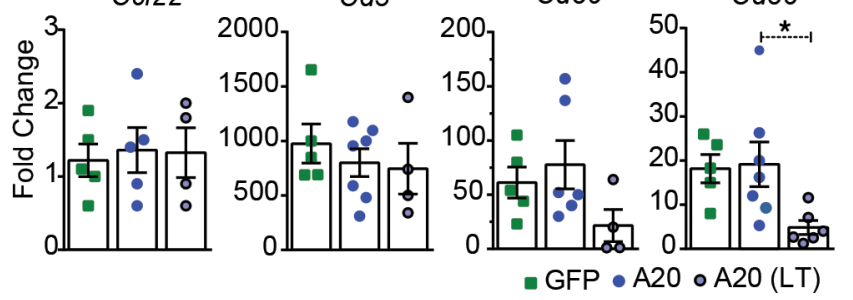
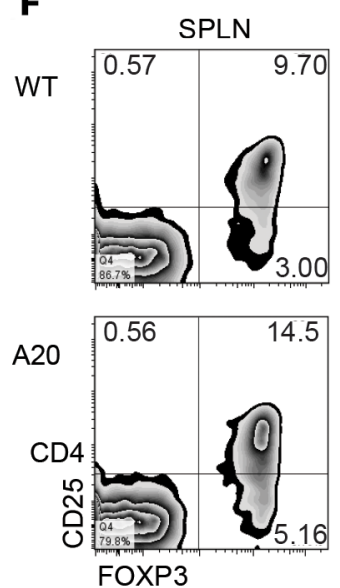
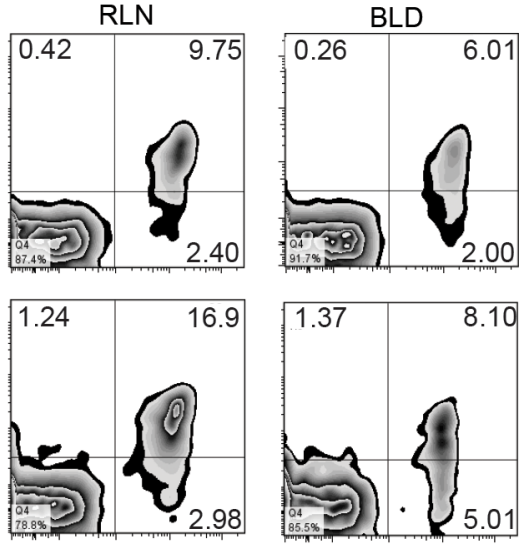

Figure 4. Long-term-surviving grafts have graft-infiltrating FOXP3+ $\mathbf{T}$ cells. (A) Representative sections of FOXP3-stained GFP- or human A20transduced islet allografts at postoperative day (POD) 10 ( $n=4$ GFP and 4 A20), (B) POD 15-25 (GFP grafts taken before rejection; $n=6$ GFP and 7 A20), and (C) POD $>100(n=6)$. Scale bar: $100 \mu \mathrm{m}$. (D) Quantification of FOXP3+ T cells. (E) GFP- or A20-expressing grafts harvested at POD 10, as well as A20-expressing long-term-surviving grafts harvested at > POD 100 and subjected to reverse transcription PCR (RT-PCR) for known immune regulatory factors. Nontransplanted overnight-cultured isolated islets were used as baseline. Each point represents an individual islet graft. (F) Flow cytometric analysis of CD4+CD25+Foxp3 ${ }^{+}$T cells from the spleen (SPLN), renal lymph node (RLN), and blood (BLD) from C57BL/6 mice (WT; $\left.n=5\right)$ and $\mathrm{C} 57 \mathrm{BL} / 6$ recipients harboring long-term-surviving $\mathrm{A} 20$ transduced grafts $(\mathrm{A} 20 ; n=5)$. Error bars $\pm \mathrm{SEM}$ and statistical significance determined by 1-way ANOVA with Tukey's multiple comparisons post hoc test; ${ }^{*} P<0.05$.

Reduced inflammation contributes to long-term allograft survival. We interpret the current data to show that A20 improves islet graft outcomes via changing graft inflammation. Among the most differentially expressed inflammatory genes in the 2 opposing situations of A20-overexpressing grafts, and A20 haploinsufficient grafts, was CXCL10 (Figure 7A) - a chemokine essential for the recruitment of T effector cells to the graft site (37-39). A20 was able to directly inhibit CXCL10 transcription, as transfection of an islet cell line with human A20 was sufficient to inhibit activation of a human CXCL10 reporter stimulated with TNF or IL1 $\beta$ alone, or a cytokine cocktail including TNF, IL-1 $\beta$, and IFN $\gamma$ (Figure 7, B and C). To test the effect of blocking CXCL10 in our islet allograft model, we administered an anti-CXCL10 mAb (2 mg/kg i.v.) to transplant recipients on the day of transplantation and every 2 days thereafter. Consequently, we found that mice receiving anti-CXCL10 mAb showed prolonged graft survival increasing from a mean survival time (MST) of 20 days $(n=5)$ up to maximum of $\sim 50$ days $(n$ $=5$ ) days after transplantation $(P=0.04)$ (Figure 7D). These experiments reveal that 1 protective effect of A20 is to change the graft inflammatory profile, as exemplified by the reduction in CXCL10, with subsequent impact upon transplant outcomes. 
A

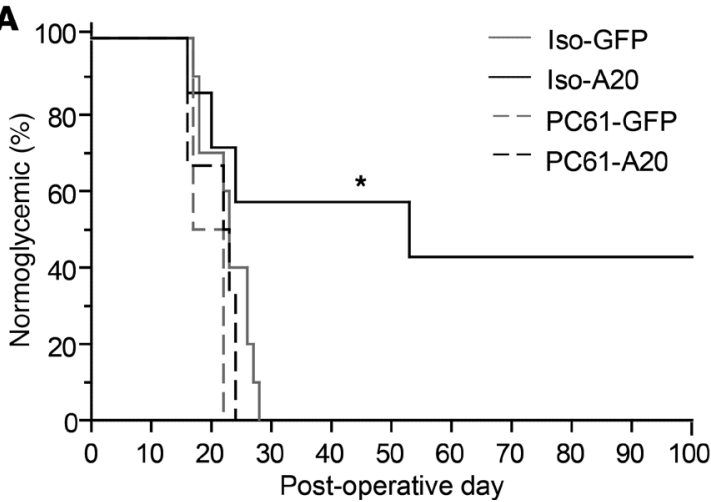

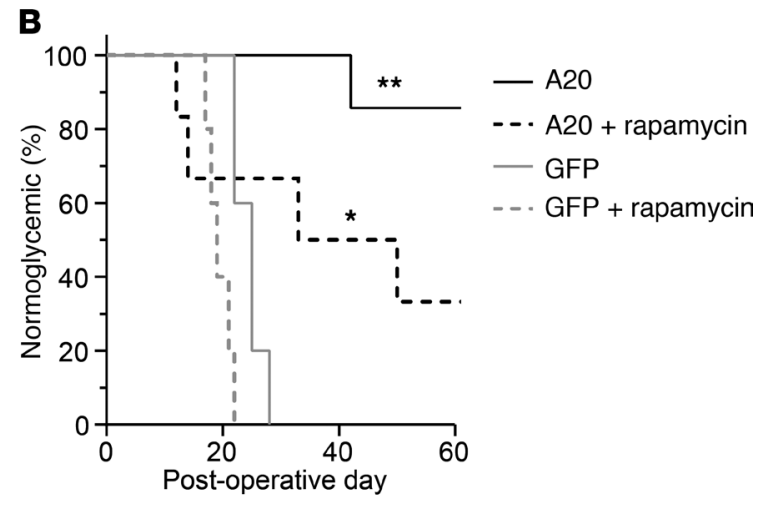

Figure 5. Administration of anti-CD25 ablates, and rapamycin enhances, the protective potential of intragraft A20 expression. (A) Percent of mice normoglycemic following the transplantation of $300 \mathrm{BALB} / \mathrm{C}$ islet expressing GFP or A20 (MOI 10:1) and transplanted under the kidney capsule of allogeneic C57BL/6 recipients. Recipient mice were administered $200 \mu \mathrm{g} \alpha \mathrm{CD25}$, clone PC61 (PC61-GFP, $n=2$; PC61-A20, $n=6$ ) or an isotype control (Iso-GFP, $n=10$; Iso-A20, $n=7$ ) on day 0 and every 10 days thereafter (Supplemental Figure 3). (B) Percent of C57BL/6 mice normoglycemic after receiving allogeneic BAL$\mathrm{B} / \mathrm{c}$ islet grafts transduced with GFP or A20 and administered a low dose of rapamycin ( $0.1 \mathrm{mg} / \mathrm{kg}$ at day of transplantation and every day thereafter for 7 days, plus RAPA, $n=7$; GFP plus RAPA, $n=5$ ) or no rapamycin (A20, $n=7$; GFP, $n=5$ ). Data is cumulative over 3 independent experiments. Significance determined by Log-rank test; ${ }^{*} P<0.05 ;{ }^{* *} P<0.01$.

Forced expression of A20 in human islets. We transduced human islets with rAd.A20 to test the clinical potential of A20 overexpression. Transduction of human islets with an adenoviral vector encoding GFP at a multiplicity of infection (MOI) of 10:1 was found to infect $\sim 60 \%$ of islet cells (Figure $8 \mathrm{~A}$ ). Increasing the MOI up to 30:1 did not significantly improve transduction rates. Immunofluorescent microscopy revealed the majority of infected transduced GFP bright cells to compose the outer cellular layer of the islet (Figure 8B). Using a MOI of 10:1, we transduced human islets with rAd.A20, which resulted in high levels of A20 mRNA and protein expression (Figure 8, C and D). A20 overexpression did not impact human islet function, as shown by the normal glucose-stimulated insulin response of rAd.A20-transduced islets (Figure 8E). However, forced expression of A20 blunted the upregulation of inflammatory genes in response to TNF stimulation (Figure $8 \mathrm{~F}$ and Supplemental Table 2).

\section{Discussion}

Here, we investigated the impact of changing A20 expression levels in islet allografts as a mechanism to modify immunostimulatory thresholds and islet allograft survival. A potential role for A20 in transplantation was first indicated in a rodent heart xenotransplantation model, where it was found that surviving hearts showed intragraft A20 expression compared with rejecting hearts (40). Further studies showed that A20 reduces endothelial inflammation during xenotransplantation (41), reduces the severity of graft arteriosclerosis (42), and improves liver graft function (43). In pancreatic islets and $\beta$ cells, A20 exerts a negative-feedback role to control inflammation. A20 expression is transcriptionally regulated in $\beta$ cells by NF- $\kappa \mathrm{B}$ activation (44) and once expressed A20 inhibits NF- $\kappa \mathrm{B}$ activation in islets $(45,46)$ by altering RIPK1 stability $(36,47)$. The fact that A20 forms a part of the natural physiological response of islets to inflammation suggests that manipulating A20 levels in islets would have a good safety profile but also have clinical potential as an approach for the suppression of otherwise deleterious NF- $\mathrm{BB}-\mathrm{dependent} \mathrm{inflam-}$ matory genes $(9,10)$. This is supported by studies showing A20 to be a potent inhibitor of NF-kB-mediated inflammation and cell death in pancreatic islets $(46,48,49)$ and by studies that show A20 expression reduces syngeneic islet graft apoptosis and improves graft metabolic control (50).

Here, we show that A20 modulates the local graft microenvironment to generate a state that has features reminiscent of allograft tolerance. The cellular mechanisms by which A20 overexpression increases tissue tolerance includes potent inhibition of $\mathrm{NF}-\mathrm{\kappa B}$ and $\mathrm{JNK} / \mathrm{AP} 1$ pathways that reduces inflammation at the graft site. The impact of A20 on NF-kB and JNK/AP1 pathways is dependent upon modification of RIPK1 polyubiquitin editing. As RIPK1 is regulated through ubiquitination $(13,47)$, this indicates that RIPK1 stability and or function at the TNF receptor represents a potential molecular node for tolerance regulation.

As a specific example of how A20 alters graft inflammation, we found the chemokine CXCL10 to be distinctly differentially regulated between A20-overexpressing and A20 I325N mutant grafts (51). 


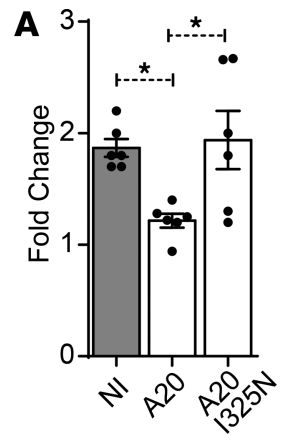

A20 (ref): +
A20 I325N: -
IKKY: +
IP. A20

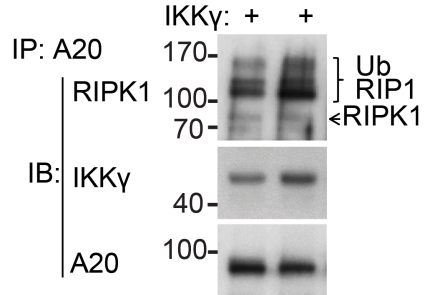

Lysates:
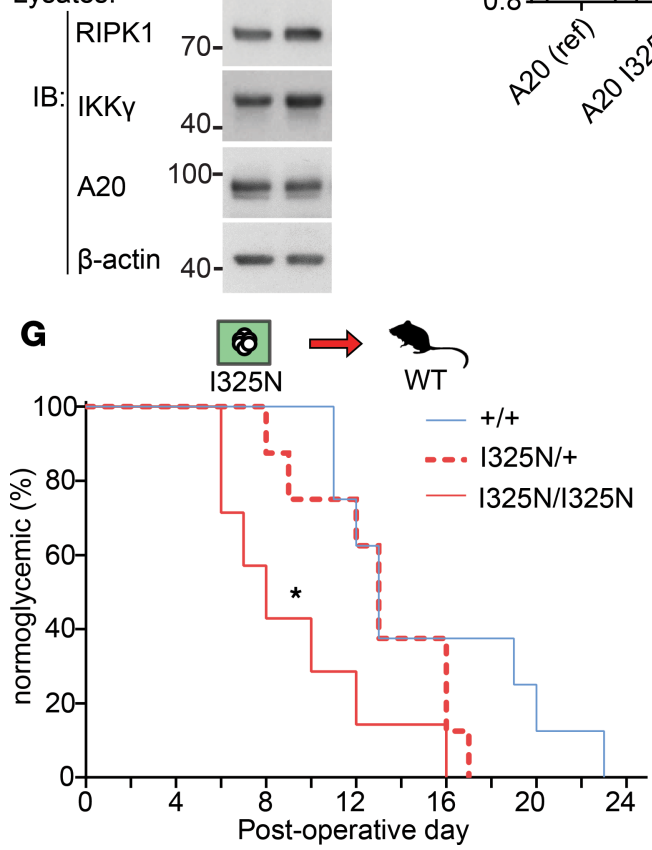
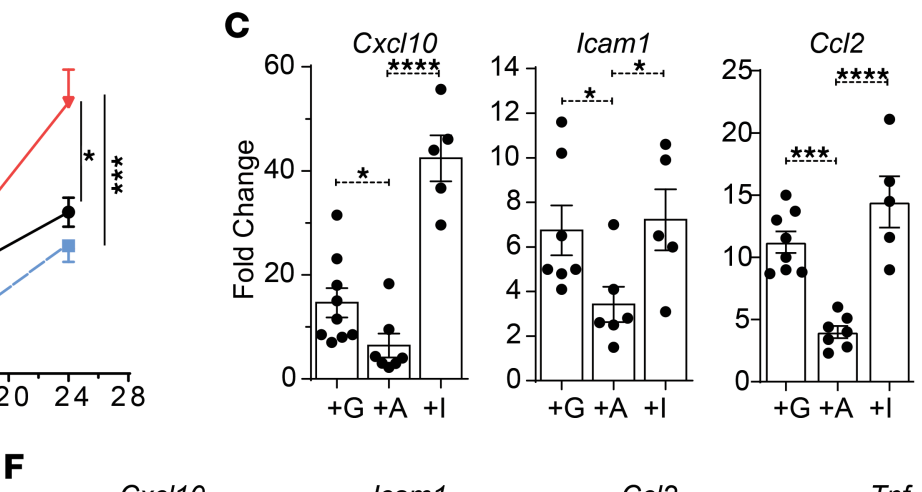

$\mathbf{F}$
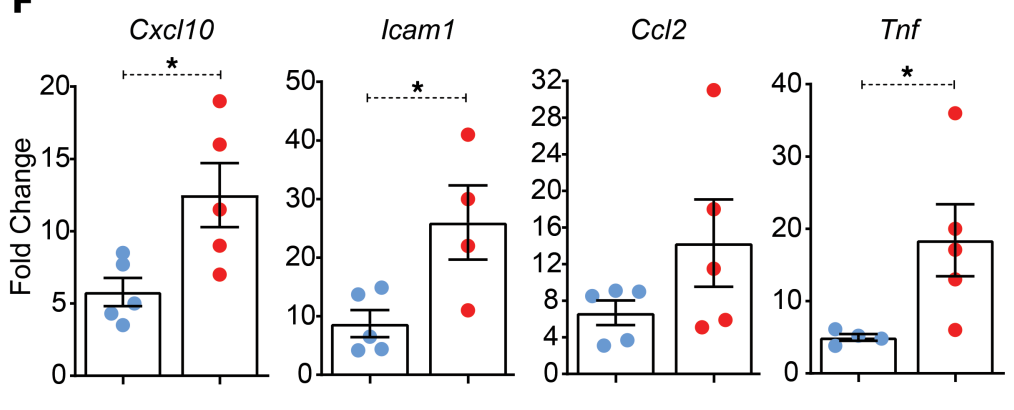

H
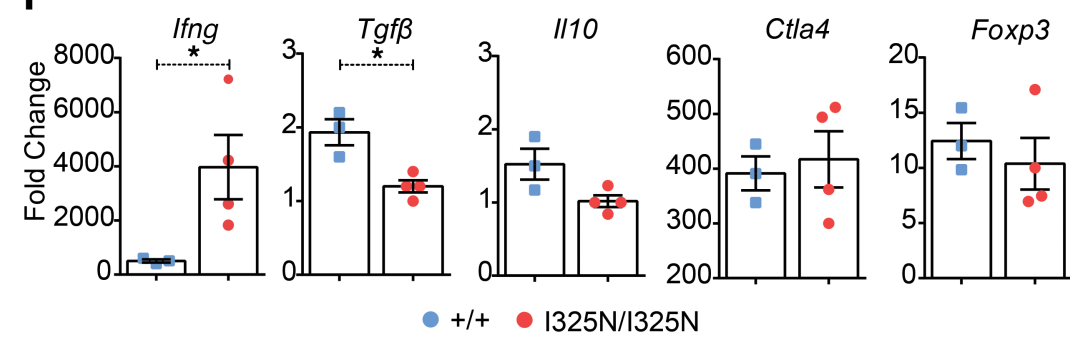

Figure 6. Reduced A20 function leads to rapid islet allograft rejection. (A and B) $\beta T C 3$ cells cotransfected with an NF- $\kappa B$.luciferase reporter (A) or an AP-1 luciferase reporter (B) and a CMV. $3 g$ al expression construct with or without PCDNA3.1-encoding murine reference A20 or A20 with an I325N coding variant. Cells were stimulated with $200 \mathrm{U} / \mathrm{mL}$ TNF for 8 hours (A); for 5, 8, 16, and 24 hours (B); or left untreated. Data represent fold change of stimulated versus nonstimulated and 3 independent experiments. (C) WT BALB/c islets were isolated and transduced with rAd.GFP (+C), rAd.TNFAIP3 (+A) or rAd.TNFAIP3 $3^{1325 \mathrm{~N}}$ (+I); incubated overnight; and stimulated with $200 \mathrm{U} / \mathrm{mL}$ TNF for 0 or 4 hours; gene expression of proinflammatory factors was assessed. Each point represents a well with 300 islets. Data cumulative over 3 independent experiments. (D) Immunoblot (IB) of A20 immunoprecipitated (IP) lysates and wholecell lysates from $\beta$ TC 3 cells transfected with reference $A 20$ or A2O I325N and IKK $\gamma$ and lysed following an overnight incubation. Membranes were probed for RIPK1, IKK $\gamma$, A20, or $\beta$-actin (loading control). (E) Densitometry of coimmunoprecipitated RIPK1 compared A20 pull-down, normalized to reference A20 (WT). Data in $\mathbf{D}$ and $\mathbf{E}$ represent 2 independent experiments and 3 biological replicates. (F) Expression of TNF-induced genes in islets from Tnfaip $3^{+/+}$or Tnfaip $3^{1325 N / 1325 N}$ mice stimulated with TNF for 4 hours. Data shown in cumulative with each point in a column representing an independent islet preparation. (G) Percent of diabetic recipient CBA $\left(\mathrm{H}^{\mathrm{k}}\right.$ ) mice normoglycemic following transplantation of 300 homozygous I325N islets (Tnfaip ${ }^{31325 N / 1325 \mathrm{~N}}$ ( $n=8$; mean survival time $[\mathrm{MST}]=8)$, heterozygous I325N $\left(\right.$ Tnfaip $\left.^{31325 N /+}\right)(n=8 ;$ MST $=13)$, or WT $\left(\right.$ Tnfaip $\left.3^{+/+}\right)(n=8 ;$ MST $=13)$ islet $\left(H 2^{b}\right)$. (H and I) Islet grafts were excised at postoperative day (POD) 10, and gene expression of known islet derived inflammatory factors (H) and nonislet derived factors (I) measured. Nontransplanted overnight-cultured isolated islets were used as baseline. Statistical significance determined by 1-way ANOVA with Tukey's multiple comparisons post hoc test (B, C, and $\mathbf{F}), 2$-tailed Student's $t$ test $(\mathbf{E}, \mathbf{H}$, and $\mathbf{I})$, or log-rank test (C). Error bars represent \pm SEM or \pm SD $(\mathbf{E})$, ${ }^{*} P<$ $0.05 ;{ }^{* *} P<0.01 ;{ }^{* *} P<0.001 ;{ }^{* * *} P<0.001$. 
A

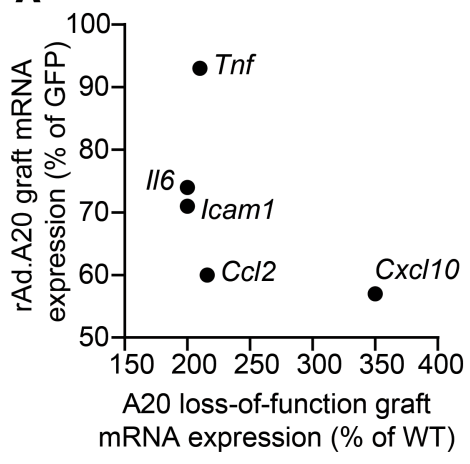

B

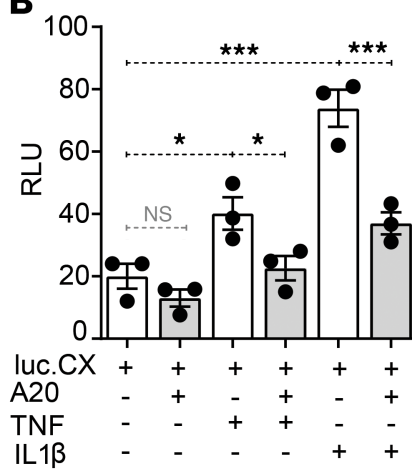

C

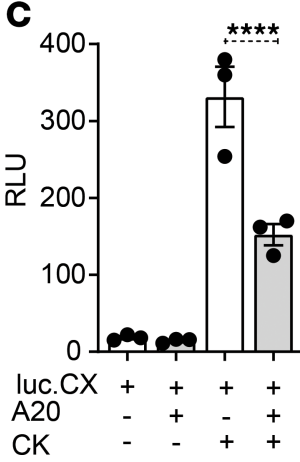

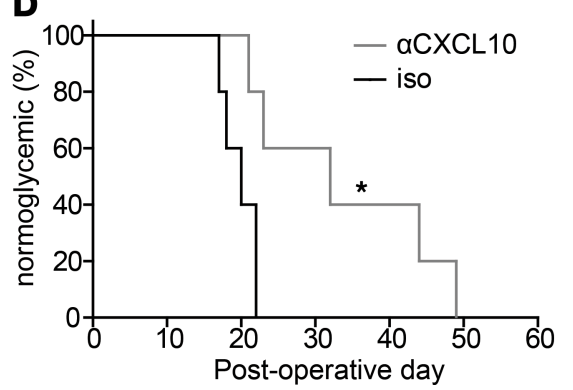

Figure 7. Differential Cxc/10 expression in A20-expressing and loss-of-function islet grafts. (A) Scatterplot comparing the expression levels (\%) of 5 inflammatory genes in allogeneic islet grafts overexpressing A2O (Figure $2 \mathrm{H}$ ) or harboring loss-of-function A20 (Figure 6H), compared with GFP-expressing control grafts harvested at postoperative day (POD) 10. (B and C) $\beta$ TC3 cells cotransfected with a CXCL10.luciferase reporter encoding the endogenous promoter (75) and a CMV.ßgal-expression construct \pm PCDNA3.1-encoding A20. Transfected cells were stimulated with (B) $200 \mathrm{U} / \mathrm{mL}$ TNF or IL-1 $\beta$, or (C) a cocktail (CK) of TNF, IL-1 $\beta$, and IFN $\gamma$ for 8 hours or left untreated. Error bars \pm SEM. Data representative of 3 independent experiments. Statistical significance determined by 1-way ANOVA with Tukey's multiple comparisons post hoc test. (D) Percent of C57BL/6 mice normoglycemic after receiving allogeneic BALB/C islet grafts and administered $2 \mathrm{mg} / \mathrm{kg}$ of an anti-CXCL10 mAb $(n=5)$ or an isotype control (iso) $(n=5)$ by tail vein injection on the day of transplantation and every 2 days thereafter. Significance determined by log-rank test, ${ }^{*} P<0.05 ;{ }^{* *} P<0.001 ;{ }^{* * *} P<0.0001$.

CXCL10 has potent antigraft effects in transplantation. CXCL10 has been demonstrated to promote immune infiltration and destruction of islets in autoimmune models (37), and it is highly expressed in insulitic lesions in patients with recent-onset T1D (52). Beyond this, CXCL10 promotes immune infiltration in islet isografts $(53)$ and allografts $(38,54)$, and is linked to poor clinical islet transplant outcomes $(9,55)$. Suppression of CXCL10 is significant as neutralization of CXCL10 can prolong graft survival in our model. Together, these data show that, by controlling RIPK1 polyubiquitination, A20 regulates signal strength through NF-KB and JNK; this in turn potently supresses graft inflammatory gene expression, such that the islet graft presents a less inflammatory image to the immune system.

mRNA transcripts altered within the graft microenvironment include cytokines that influence $\mathrm{T}$ cell polarization - namely, increased transcripts for TGF $\beta$ and IL10 - and reduced transcripts for IL6 and TNF (56-59). Bettelli et al. (56) showed a cytokine-dependent development dichotomy between Tregs and cytotoxic Th17 cells, largely based on a balance between TGF $\beta$ and IL- 6 levels, whereby TGF $\beta$ in the presence of IL- 6 supports Treg differentiation. Together, our data show that A20 can promote tolerance by modulating the inflammatory milieu of the islet graft. The altered graft microenvironment engenders the local maintenance of Foxp $3^{+}$Tregs at the graft site, providing long-term graft acceptance.

The cytokine milieu supporting graft rejection represents a promising therapeutic target, as increasing the levels of BAFF (60), IL-2 (61), or IL-2 while simultaneously blocking IL-15 (62) can result in stable allograft tolerance in rodent transplant models. As a different approach than systemic approaches, here we show blunting inflammatory cytokine and chemokine production within the graft microenvironment by increasing intragraft A20 harnesses Foxp3-expressing Tregs and limits inflammatory T cell recruitment.

It is of interest to consider whether, once allograft tolerance is established, Tregs are required for the continued maintenance phase. In experiments not shown, we treated mice with long-term-surviving ( $>100$ days) 
A

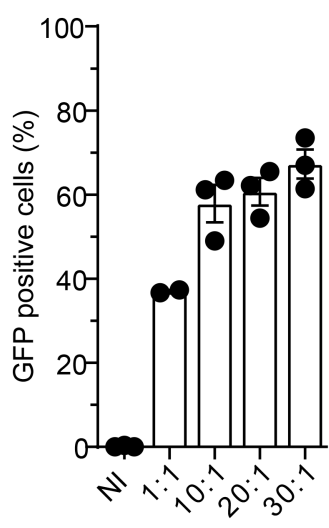

C

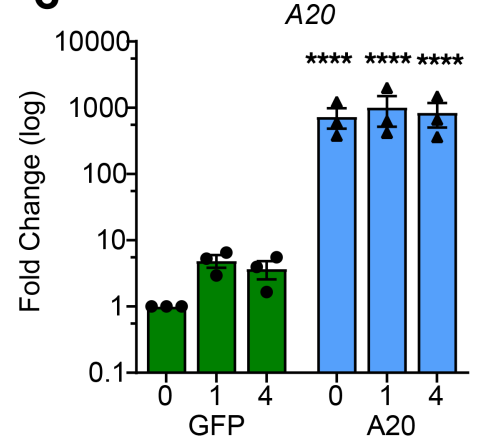

B
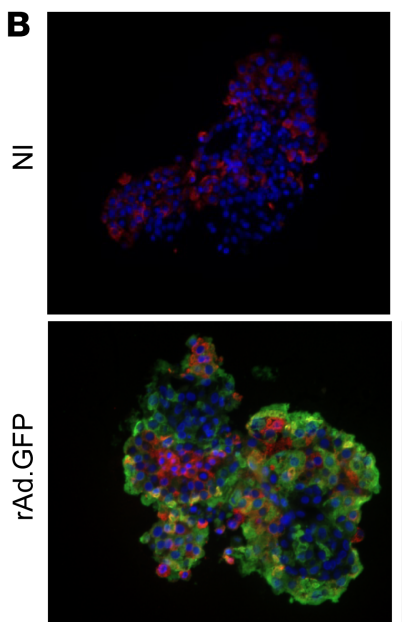

Dapi Insulin GFP
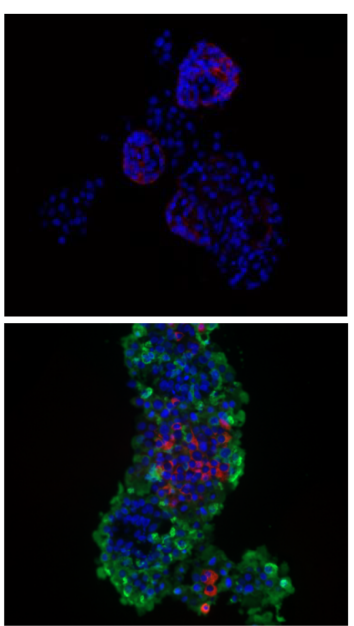

Dapi Glucagon GFP
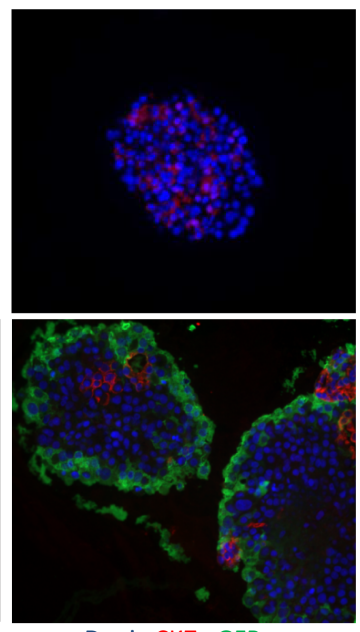

Dapi CK7 GFP

D
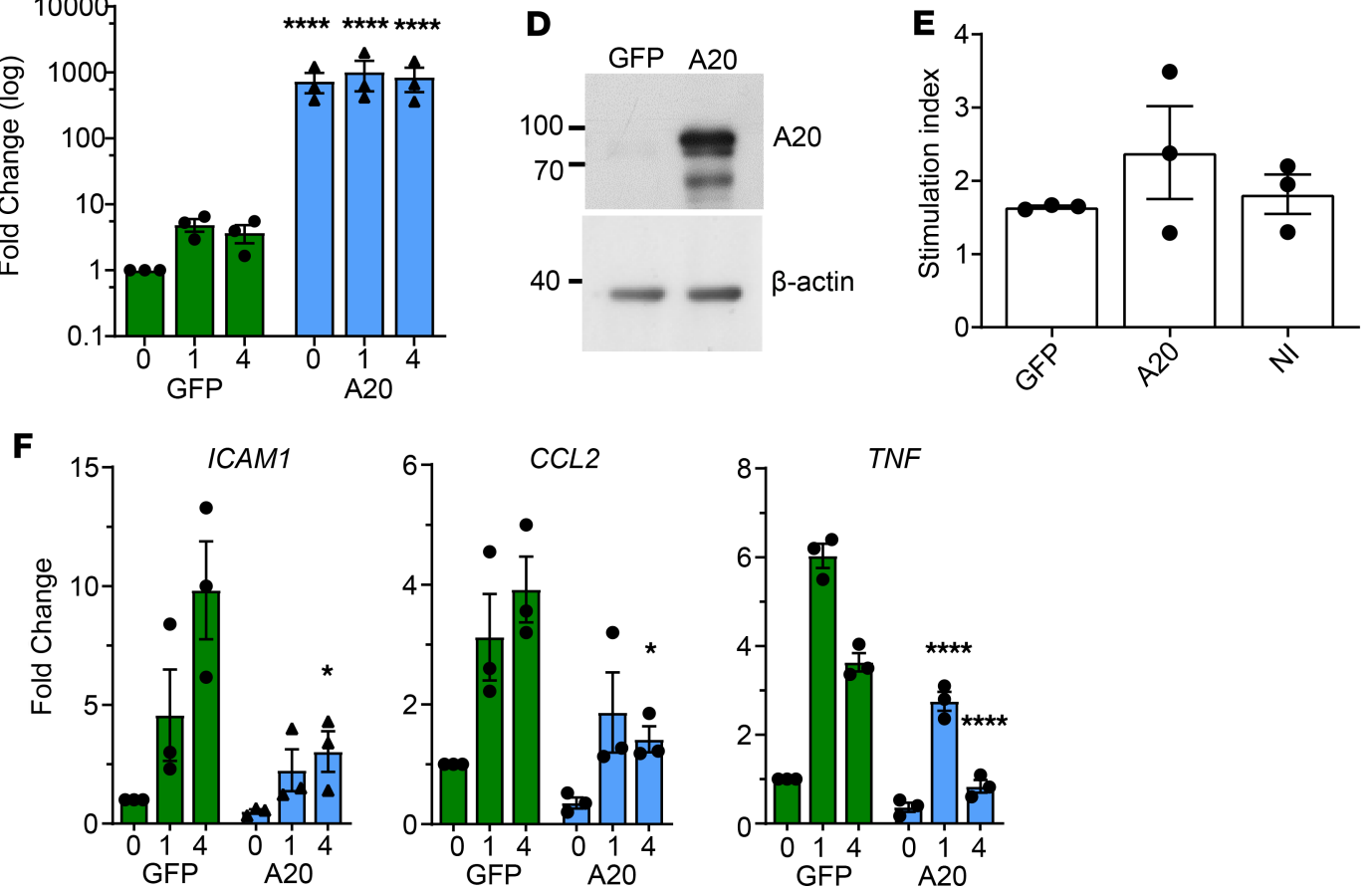

Figure 8. A20 expression inhibits human islet inflammation. (A) Human islets transduced with an adenovirus encoding for GFP (rAd.GFP) at multiplicity of infections indicated or left noninfected (NI). Twenty-four hours after transduction, islets were digested to single cells, and the percent of GFP+ cells was determined by flow cytometry. Each dot per column represents an independent human donor. (B) Donor human islet preparations were transduced with rAd.GFP at a $\mathrm{MOI}$ of 10:1 or left noninfected (NI). Forty-eight hours after transduction, islets were fixed for immunofluorescence analysis. Assessed proteins are indicated below each panel. Scale bar: $50 \mu \mathrm{m}$. (C and D) Donor human islets transduced with rAd.GFP or A20 at a MOI of 10:1. Forty-eight hours after transduction, cells were lysed and assessed for (C) A20 RNA expression and (D) protein levels. (E) Function of infected islets were assessed in a glucose-stimulated secretion assay. Stimulation index indicates the amount of insulin in supernatant in high glucose/low glucose. (F) GFP- and A20-transduced donor islets stimulated with TNF for the indicated times and expression of inflammatory genes assessed. Data in $\mathbf{A}-\mathbf{F}$ are cumulative from 3 independent human donor islet preparations. Error bars \pm SEM and statistical significance determined by 2-way ANOVA with Sidak's multiple comparisons post hoc test; ${ }^{*}<<0.05 ;{ }^{* * *} P<0.0001$.

and A20-expressing islet allografts with 4 doses of PC61 mAb every 10 days to reduce Tregs or with a single dose of FTY720 to sequester T cells within lymph nodes (63). In both experiments, graft function remained stable, and no grafts were lost. These results are consistent with previous studies that manipulate Tregs showing a central role for Tregs in the early acceptance phase of allograft tolerance but not the later phase, where established tolerance is relatively robust to Treg depletion $(60,61)$. These data suggest that different mechanisms are involved once stable engraftment has occurred. Indeed, A20 expression has been previously identified as a factor contributing to long-term-surviving vascular xenografts without evidence of ongoing immune reactivity in a process referred to as "accommodation" (40). 
Different to its known role in controlling immune cell activation thresholds (15-21), our data highlight TNFAIP3 as a crucial gene for the maintenance of tissue tolerance via its role in dampening islet responses to $\mathrm{NF}-\mathrm{\kappa B}$-inducing inflammatory mediators. A20 plays a central role to maintain intestinal tolerance, where a loss of A20 leads to aberrant responses to gut microbiota with intestinal inflammation $(21,64)$. The requirement of A20 for tissue homeostasis, as well as immune cell activation, may be a potent contributing factor driving the genome-wide association study (GWAS) association of A20 with many autoimmune and inflammatory disorders (65). Furthermore, A20 haploinsufficient human subjects present with increased Th17 cells and inflammatory disease $(22,23)$, whereas mice with A20 germline deficiency succumb to uncontrolled inflammation (66).

Here, we show that manipulating A20 levels to achieve tissue tolerance can be directed to improve islet transplantation outcomes by changing the inflammatory environment at the graft site, which subsequently alters the instructive signals received by $\mathrm{T}$ cells, leading to an altered balance of Tregs that favors immunological tolerance. Our findings indicate that the strategy of increasing A20 expression in the graft will likely synergize well with 2 classes of drugs: (a) Treg-promoting compounds such as rapamycin (30-33), antiIL-2 mAb (61, 62), and/or local expression of the Treg attractant CCL22 (67), and (b) antiinflammatory drugs that target TNF and IL-1 $\beta$ pathways $(7,68)$.

\section{Methods}

Animal models. C57BL/6 and BALB/c mice were purchased from the Animal BioResource Centre. RAG ${ }^{-1}$ and CBA mice were purchased from the Australian Resources Centre. Male, inbred, B6.129S7-Rag1 ${ }^{\mathrm{tm} 1 \mathrm{Mom} / \mathrm{J}}$ mice were purchased from the Jackson Laboratory. Mice were used at 8-10 weeks of age for all experiments.

Mouse islet isolation and transplantation. Islets were isolated as previously described (49) and were counted for islet transplantation or in vitro experiments using a Leica MZ9.5 stereomicroscope. Three hundred islets were transplanted under the kidney capsule of diabetic C57BL/6 littermates (50). This strain combination represents a complete MHC mismatch. Diabetes was induced by i.p. injection of 180 $\mathrm{mg} / \mathrm{kg}$ streptozotocin (Sigma-Aldrich) dissolved in $0.1 \mathrm{M}$ citrate buffer ( $\mathrm{pH} 4.2$ ) at a concentration of 20 $\mathrm{mg} / \mathrm{mL}$. Diabetes was determined as [blood glucose] $\geq 16 \mathrm{mM}$ on 2 consecutive days measured by FreeStyle Lite glucometer and Abbott Diabetes Care test strips following tail tipping. In some experiments, transplanted mice were treated with rapamycin, anti-CD25 (clone PC61) monocolonal antibody (WEHI Antibody Services), or anti-CXCL0 monoclonal antibody (gift of Charles Mackay; Monash Biomedicine Discovery Institute, Monash University, Clayton Victoria). Rapamycin (LC laboratories) was dissolved in vehicle solution $(0.2 \%$ carboxylethyl cellulose, $0.25 \%$ polysorbate- 80 in $0.9 \% \mathrm{NaCl})$ and administered by i.p. injection on the day of transplantation and every day thereafter for 7 days. PC61 was used for in vivo depletion of $\mathrm{CD} 4{ }^{+} \mathrm{CD} 25^{+} \mathrm{T}$ cells; mice were injected with purified rat anti-mouse CD25 IgG1 mAb (PC61; BioExpress) i.v. (200 $\mu \mathrm{g})$ on the day of transplantation and every 10 days thereafter. The efficacy of CD25 depletion was confirmed by flow cytometry. Anit-CXCL10 was administered at $2 \mathrm{mg} / \mathrm{kg}$ by tail vein injection on the day of transplantation and every 2 days thereafter (gift from Charles MacKay; Department of Immunology, Monash University, Melbourne, Australia). Islet grafts were retrieved from recipients at indicated time points after transplantation for analysis of islet morphology, degree of lymphocytic infiltration by histology, or gene expression by quantitative PCR (qPCR). Gene expression in islet grafts was calculated using the average WT $\Delta \mathrm{Ct}$ value. Islets to be used for in vitro studies were cultured overnight in islet overnight culture media (RPMI-1640 [Thermo Fisher Scientific], 20\% FCS [Thermo Fisher Scientific], $100 \mathrm{U} / \mathrm{mL}$ penicillin and streptomycin [P/S; Sigma-Aldrich], 2 mM L-glutamine [Sigma-Aldrich]) at $37^{\circ} \mathrm{C}$ plus $5 \% \mathrm{CO}_{2}$.

Adoptive transfer. $\mathrm{RAG}^{-/-}$mice were pretransplanted with an islet graft and left to rest for 14 days. Following 14 days, spleens were obtained from mice harboring long-term-surviving grafts. Harvested spleens were prepared by mechanical disruption to single cell suspensions, and erythrocytes were removed by osmotic lysis with sterile $\mathrm{RBC}$ lysis solution $(0.156 \mathrm{M}$ ammonium chloride, $0.01 \mathrm{M}$ sodium hydrogen carbonate, $1 \mathrm{mM}$ EDTA; Sigma-Aldrich) and filtered through 70- $\mu$ m nylon strainer (Becton Dickinson). $\mathrm{CD}^{+}$and $\mathrm{CD}^{+} \mathrm{T}$ cell subsets were isolated via magnetic separation using Pan $\mathrm{T}$ cell kit (Miltenyi Biotec). Effector T cells (CD25-) were isolated from $\mathrm{T}$ cell populations by positive depletion of $\mathrm{CD} 25^{+} \mathrm{T}$ cells using the CD25 MicroBead kit following manufacturer's instructions. Magnetic separations were performed using AUTOMACS (Miltenyi Biotec), to a purity $>95 \%$, as assessed by flow cytometric analysis, described below. Splenocytes T cells $\left(2 \times 10^{7}\right)$, T cells $\left(2 \times 10^{6}\right)$, or effector T cells $\left(2 \times 10^{6}\right)$ were adoptively transferred via tail vein injection. 
Cell lines. Min6 cells, generated by ref. 69, are derived from the pancreatic $\beta$ cells of transgenic mice and immortalized by tranduction with $\mathrm{T}$ antigen of simian virus 40 (SV40). MIN6 cells retain the ability to secrete insulin $(70,71)$. Cells were maintained in DMEM supplemented with 10\% FCS, $2 \mathrm{mM}$ L-glutamine, $12.5 \mathrm{mM}$ HEPES (Thermo Fisher Scientific), 0.002\% $\beta$-mercaptoethanol (MilliporeSigma), and 1\% (100 U/mL) penicillin/streptomycin (Thermo Fisher Scientific) and incubated at $37^{\circ} \mathrm{C}$ in $5 \% \mathrm{CO}_{2}$. Passage $31-40$ was used for experiments (71). $\beta$ TC3 cells, derived from insulinoma cells that arise in the pancreatic $\beta$ cells of transgenic mice expressing SV40 T antigen under the control of the rat insulin II promoter (RIP) $(72,73)$. These cells were cultured in RPMI supplemented with $10 \%$ fetal calf serum, $4 \mathrm{mM}$ L-glutamine, and $100 \mathrm{U} / \mathrm{mL}$ penicillin/streptomycin (Thermo Fisher Scientific) and incubated at $37^{\circ} \mathrm{C}$ in $5 \% \mathrm{CO}_{2}$. A passage $21-40$ was used for experiments. The source for all cell lines was American Tissue Culture Collection.

rAd-mediated gene transfer. Islets and insulinoma MIN6 cells were transduced with rAd to over-express GFP (rAd.GFP) or A20 (rAd.A20), as described previously (48, 49). For islet gene transduction, islets were inoculated with virus at the stated MOI and incubated for 1.5 hours at $37^{\circ} \mathrm{C}$ in $0.5 \mathrm{~mL}$ serum free RPMI-1640 medium (Thermo Fisher Scientific). Islets were then ready for further culture or transplantation. MIN6 cells were plated at a density of approximately $1 \times 10^{6}$ /well in 6-well tissue culture plates (Corning CoStar) and inoculated with virus at the optimal MOI of 100:1 in DMEM (Thermo Fisher Scientific). After 1.5 hours, cells were replenished with DMEM 10\% FCS and cultured a further 24 hours before use. Adenovirus was propagated by infecting HEK293 cells in six T175 vented flasks (Coring CoStar). Cells were lysed and adenoviruses were extracted using Aenopure kit according to instructions provided (PureSyn Inc.). The purified virus was titrated and quantified in HEK293 cells using the Adeno-X Rapid Titer Kit (Clontech) according to manufacturer's instructions.

Transgene expression. GFP expression was determined by fluorescent microscopy, and images were captured under a Zeiss inverted fluorecence microscope (Carl Zeiss Inc.). Islets expressing GFP were made to a single cell suspension with $0.1 \%$ trypsin and run through a CytoFLEX (Beckman) or CantoII (BD Biosciences) flow cytometer to determine GFP expression level. For A20 and IкB $\alpha$ protein expression, primary islets or MIN6 cells were cultured for 24 hours after gene transduction and lysed in radioimmunoprecipitation (RIPA) buffer; about $10 \mu \mathrm{g}$ of total protein was resolved on a $10 \%$ SDS PAGE gel and then transferred to a nitrocellulose membrane. Membranes were incubated with polyclonal anti-A20 (Abcam, 59A426) and anti-IкB $\alpha$ (Cell Signaling Technology, 9242) and followed by peroxidase-labeled secondary antibodies. Signals were visualized using an ECL detection kit (Amersham Pharmacia Biotech).

Reporter assays. Reporter assays were carried out essentially as we have described (44, 74). For NF- $\mathrm{B}$ activity, $\beta$ TC 3 cells were transfected with $0.3 \mu \mathrm{g}$ of a NF- $\kappa B$.luciferase reporter, $0.20 \mu \mathrm{g}$ CMV. $\beta$-galactosidase (CMV. $\beta \mathrm{gal})$, and $0.5 \mu \mathrm{g}$ of the mammalian expression vector pcDNA encoding human A20, or as a control, empty vector. AP-1 activity was determined by the Cignal AP1 Reporter (luc) Kit (SABiosciences) according to the manufactures instructions. Transfection was conducted using lipofectamine 2000 (Invitrogen) as per the manufacturer's instructions. Following transfection, cells were stimulated with $200 \mathrm{U} / \mathrm{mL}$ of TNF or $200 \mathrm{U} / \mathrm{mL}$ of each IL1 $\beta$, TNF, and INF $\gamma$ (R\&D Systems). Luciferase activity was assayed in cell lysates harvested 8 hours after stimulation, using a luciferase assay kit (Promega). Results were normalized to $\beta$-galactosidase or Renilla activity (Galactostar) to give relative luciferase activity. Expression plasmids and reporters were obtained and maintained as described previously $(44,74)$. CXCL10 endogenous reporter (GL-IP10) (75) was a gift from Richard Ransohoff's laboratory (Third Rock Ventures).

IHC. Tissues were fixed in 10\% neutral buffered formalin (Sigma-Aldrich) and paraffin embedded, and parallel sections $(5 \mu \mathrm{m})$ were prepared. Sections were stained with H\&E (Sigma-Aldrich) or for insulin, FOXP3, CD4, or CD8 followed by counterstain with hematoxylin. To stain for insulin, purified rabbit antimouse insulin polyclonal antibody was used (4950, Cell Signaling Technology), followed by an HRP-labelled polymer-conjugated goat anti-rabbit IgG (Dako EnVision+ System, Agilent) with DAB substrate (Sigma-Aldrich), used for visualization. To stain for FOXP3, antigen retrieval was first performed using a pressure cooker (Dako Cytomation), filled with $10 \mathrm{mM}$ citrate, $\mathrm{pH} 6$ (Dako Cytomation), and set to $125^{\circ} \mathrm{C}$ with 30 seconds at the maximal pressure set to 10 psi. Polyclonal anti-mouse/rat FOXP3 (eBioscience, 14-5773-82) was used for primary antibody staining of FOXP3 antigen (FJK-16S, eBioscience), followed by secondary biotin antirat with spacer to amplify the signal (112-066-071, Jackson ImmunoReseach Laboratories), and visualization of the signal was achieved by using Vectastain Elite ABC kit (Vector Laboratories). CD4 and CD8 staining of paraffin sections was conducted at St. Vincent Hospital (Darlinghurst, Australia) clinical histology core. Images were captured using a Leica DM 4000 (Leica Microsystems). 
Immunofluorescence was performed on paraffin sections, as previously described (76). Primary antibodies included anti-insulin (IR00261-2, DAKO), anti-glucagon (G2654, Sigma-Aldrich), anti-cytokeratin (CK) 7 anti-A20 (M7018, AbCAM), and anti-A20 (PA-20728, Thermo Fisher Scientific). All appropriate species-specific secondary antibodies were AlexaFluor 488 or -594 conjugates (Thermo Fisher Scientific) and diluted 1/200 in 5\% normal goat serum. Slides were coverslipped with ProLong Gold antifade reagent with DAPI (Thermo Fisher Scientific) to counterstain nuclei and preserve fluorescence.

Immunoblot analysis and immunoprecipitation. Primary islets were lysed in islet lysis buffer (50 mM Tris-HCL, pH 7.5, 1\% Triton X, 0.27 M sucrose, 1 mM EDTA, 0.1 mM EGTA, 1 mM Na3VO4, 50 mM NaF, 5 mM 1044 $\mathrm{Na}_{4} \mathrm{P}_{2} \mathrm{O}_{7}, 0.1 \% \beta$-mercaptoethanol; supplemented with EDTA-free protease inhibitor 1045 [Roche]) and cell lines were lysed with RIPA buffer with SDS, following relevant treatment with or without $200 \mathrm{U} / \mathrm{mL}$ of recombinant human TNF (R\&D Systems). Protein concentration was measured using the Bradford assay (Bio-Rad), and total protein $(20-25 \mu \mathrm{g})$ was resolved on a $7 \%-10 \%$ SDS PAGE gel and then transferred to a nitrocellulose membrane, Immobilon-P (Merck Millipore). Immunoprecipitation was conducted by first preclearing lysates with protein A/G-Sepharose (Thermo Fisher Scientific) for 1 hour and then incubated with anti-A20 antibody (59A426, Abcam) or anti-IKK $\gamma\left(2585\right.$, Cell Signaling Technology) for 2 hours at $4^{\circ} \mathrm{C}$. Following incubation with only antibody, $25 \mu \mathrm{L}$ of protein $\mathrm{A} / \mathrm{G}$ beads were added and incubated at $4^{\circ} \mathrm{C}$ on a roller overnight. Beads were washed $4 \times$ with lysis buffer and then eluted with $30 \mu \mathrm{L}$ of Laemmli reducing gel-loading sample buffer. Samples were vortexed, heated to $100^{\circ} \mathrm{C}$ for 5 minutes, cooled on ice for 10 minutes, and then loaded onto an $8 \%-10 \%$ agarose gel for immunoblotting. Membranes were incubated with anti-A20 (catalog 56305/D13H3), anti-IкBa (catalog 9242), anti-IKK $\gamma$ (catalog 2585), anti-JNK (catalog 9252), and anti phospho-JNK (catalog 9255) (all Cell Signaling Technology); anti-RIPK1 (610458, BD Biosciences); or anti- $\beta$-actin (AC15, Sigma-Aldrich), followed by horseradish peroxidase-labeled (HRP-labeled) secondary antibody goat anti-mouse IgG Fc (Pierce Antibodies, 31439) or donkey anti-rabbit IgG (GE Life Sciences, NA934V). HRP conjugates bound to antigen were detected and visualized by using an ECL detection kit (GE Life Sciences).

$q P C R$. Mouse islets or neonatal porcine were isolated and placed into 12-well non-tissue culture-treated plates (150-200 islets/well; Thermo Fisher Scientific). Following an overnight culture, cells were treated with $200 \mathrm{U} / \mathrm{mL}$ recombinant human TNF or each of IL-1 $\beta$, TNF, and INF $\gamma$ (R\&D Systems). In some experiments, cells were also pretreated with pharmacological inhibitors pyrrolidine dithiocarbamate (PDTC) and SP600125 (Sigma-Aldrich). Inhibitors were added at listed concentrations and incubated with cells at $37^{\circ} \mathrm{C}$ for 1.5 hours prior to cytokine stimulation or islet transplantation. Total RNA was extracted using the RNeasy Plus Mini Kit (Qiagen) and reverse transcribed using Quantitect Reverse Transcription Kit (Qiagen). Primers were designed using Primer3 (77) with sequences obtained from GenBank and synthesized by Sigma-Aldrich (Supplemental Tables 1 and 2). PCR reactions were performed on the LightCycler 480 Real Time PCR System (Roche) using the FastStart SYBR Green Master Mix (Roche). Cyclophilin (CPH2) and ACTB were used as housekeeping genes, and data were analyzed using the $2^{\Delta \triangle \mathrm{CT}}$ method. Initial denaturation was performed at $95^{\circ} \mathrm{C}$ for 10 seconds, followed by a 3-step cycle consisting of $95^{\circ} \mathrm{C}$ for 15 seconds $\left(4.8^{\circ} \mathrm{C} / \mathrm{s}\right.$, denaturation), $63^{\circ} \mathrm{C}$ for 30 seconds $\left(2.5^{\circ} \mathrm{C} / \mathrm{sec}\right.$, annealing), and $72^{\circ} \mathrm{C}$ for 30 seconds $\left(4.8^{\circ} \mathrm{C} / \mathrm{s}\right.$, elongation). A melt curve was performed after finalization of 45 cycles at $95^{\circ} \mathrm{C}$ for 2 minutes, $40^{\circ} \mathrm{C}$ for 3 minutes, and a gradual increase to $95^{\circ} \mathrm{C}$ with 25 acquisitions $/{ }^{\circ} \mathrm{C}$.

Flow cytometry. Flow cytometry staining was performed as described (27). Mouse lymphocytes were incubated with the following fluorochrome-conjugated antibodies: CD4 (clone RM4-5), CD8 (clone 53-6.7), CD3 (clone 17A2), CD25 (clone PC61.5), CD44 (clone IM7), and CD62L (clone MEL-14) (all from BioLegend); B220 (clone RA3-6B2, BD Biosciences); and FOXP3 (clone FJK-165, eBioscience). Data were acquired with CytoFLEX (Beckman) or CantoII (BD Biosciences) flow cytometer and analyzed using FlowJo software (Tree Star Inc.).

Statistics. All data are presented as mean \pm SEM or \pm SD. Two-tailed Student's $t$ test, or 1- or 2-way ANOVA analysis, with Tukey's or Sidak's multiple comparison post hoc tests, were performed, depending on experimental design, to determine statistical difference between groups. A $P$ value less than 0.05 was considered significant. For allograft survival, day of rejection was plotted as Kaplan-Meier curves and analyzed using the Log-rank test. Tests were conducted on Prism (v8) software (GraphPad Software).

Study approval. All procedures involving animals were carried out according to the guidelines established by the Australian Institutional Animal Ethics Committee guidelines. Animal studies were approved by the Garvan/St. Vincent's Animal Ethics Committee. All procedures performed complied with the Australian Code of Practice for Care and Use of Animals for Scientific Purposes. Human islets 
were obtained from Alberta Diabetes Institute IsletCore (University of Alberta) (78). Ethics approval for work with human tissue was obtained from the Health Research Ethics Board, Biomedical Panel, University of Alberta (Study ID Pro00001416).

\section{Author contributions}

NWZ, SNW, and STG were responsible for mouse islet isolation, transplantation experiments, and adoptive transfer experiments and analysis. NWZ and STG performed molecular studies for cell lines and islets, and analyzed results. NWZ and STG analyzed $1325 \mathrm{~N}$ mice. NWZ, KLS, PJO, and GSK performed human islet experimentation and analysis. STG, NWZ, and STG cowrote the manuscript. All authors read and approved the manuscript. STG conceived and designed the study.

\section{Acknowledgments}

We thank Jeanette Villanueva (Victor Chang Cardiac Research Institute, Sydney, Australia) for technical advice regarding the administration and use of PC61 mAb and Bernice Tan (Garvan Institute of Medical Research, Sydney, Australia) for technical advice regarding NF- $\mathrm{B}$ reporter assays and transfection assays with MIN6 cells. We thank Christopher Goodnow (Garvan Institute of Medical Research, Sydney, Australia) for providing ENU-generated mice harboring the I325N A20 mutation. We thank Richard Ransohoff (Third Rock Ventures) for the CXCL10 endogenous reporter. We thank Charles MacKay for provision of anti-CXCL10 antibody (Department of Immunology, Monash University, Melbourne, Australia). NWZ was supported by an Australian Postgraduate Award and is an International Pancreas and Islet Transplant Association (IPITA) Derek Gray Fellow. The research was supported by grants to GSK from CIHR (MOP 119500) and to STG from the NSW Office for Health and Medical Research and the NHMRC (596825, 1130222), as well as a ARC and JDRF grant (4-SRA-2016-265-M-B). STG is a NHMRC Senior Research Fellow (1140691).

Address correspondence to: Shane T. Grey, 384 Victoria Street, Darlinghurst NSW 2010, Australia. Phone: 61.2.92958104; Email: s.grey@garvan.org.au.

1. Todd JA. Etiology of type 1 diabetes. Immunity. 2010;32(4):457-467.

2. Schuetz C, et al. $\beta$ Cell Replacement Therapy: The Next 10 Years. Transplantation. 2018;102(2):215-229.

3. Holmes-Walker DJ, et al. Islet Transplantation Provides Superior Glycemic Control With Less Hypoglycemia Compared With Continuous Subcutaneous Insulin Infusion or Multiple Daily Insulin Injections. Transplantation. 2017;101(6):1268-1275.

4. Shapiro AM, et al. International trial of the Edmonton protocol for islet transplantation. N Engl J Med. 2006;355(13):1318-1330.

5. O'Connell PJ, et al. Multicenter Australian trial of islet transplantation: improving accessibility and outcomes. Am J Transplant. 2013;13(7):1850-1858.

6. Shapiro AM, et al. Islet transplantation in seven patients with type 1 diabetes mellitus using a glucocorticoid-free immunosuppressive regimen. $N$ Engl J Med. 2000;343(4):230-238.

7. Shapiro AM, Pokrywczynska M, Ricordi C. Clinical pancreatic islet transplantation. Nat Rev Endocrinol. 2017;13(5):268-277.

8. Al-Adra DP, et al. Single-donor islet transplantation and long-term insulin independence in select patients with type 1 diabetes mellitus. Transplantation. 2014;98(9):1007-1012.

9. Cowley MJ, et al. Human islets express a marked proinflammatory molecular signature prior to transplantation. Cell Transplant. 2012;21(9):2063-2078

10. Zammit NW, Grey ST. Equipping the islet graft for self defence: targeting nuclear factor $\kappa \mathrm{B}$ and implications for tolerance. Curr Opin Organ Transplant. 2018;23(1):97-105.

11. Cantley J, et al. A preexistent hypoxic gene signature predicts impaired islet graft function and glucose homeostasis. Cell Transplant. 2013;22(11):2147-2159.

12. Abdelli $\mathrm{S}$, et al. Intracellular stress signaling pathways activated during human islet preparation and following acute cytokine exposure. Diabetes. 2004;53(11):2815-2823.

13. Wertz IE, et al. De-ubiquitination and ubiquitin ligase domains of A20 downregulate NF-kappaB signalling. Nature. 2004;430(7000):694-699.

14. Boone DL, et al. The ubiquitin-modifying enzyme A20 is required for termination of Toll-like receptor responses. Nat Immunol. 2004;5(10):1052-1060

15. Song XT, Evel-Kabler K, Shen L, Rollins L, Huang XF, Chen SY. A20 is an antigen presentation attenuator, and its inhibition overcomes regulatory T cell-mediated suppression. Nat Med. 2008;14(3):258-265.

16. Kool M, et al. The ubiquitin-editing protein A20 prevents dendritic cell activation, recognition of apoptotic cells, and systemic autoimmunity. Immunity. 2011;35(1):82-96.

17. Hong B, Song XT, Rollins L, Berry L, Huang XF, Chen SY. Mucosal and systemic anti-HIV immunity controlled by A20 in mouse dendritic cells. J Clin Invest. 2011;121(2):739-751.

18. Tavares RM, et al. The ubiquitin modifying enzyme A20 restricts B cell survival and prevents autoimmunity. Immunity. 
2010;33(2):181-191.

19. Chu Y, et al. B cells lacking the tumor suppressor TNFAIP3/A20 display impaired differentiation and hyperactivation and cause inflammation and autoimmunity in aged mice. Blood. 2011;117(7):2227-2236.

20. Matmati M, et al. A20 (TNFAIP3) deficiency in myeloid cells triggers erosive polyarthritis resembling rheumatoid arthritis. Nat Genet. 2011;43(9):908-912.

21. Vereecke L, et al. Enterocyte-specific A20 deficiency sensitizes to tumor necrosis factor-induced toxicity and experimental colitis. J Exp Med. 2010;207(7):1513-1523.

22. Zhou Q, et al. Loss-of-function mutations in TNFAIP3 leading to A20 haploinsufficiency cause an early-onset autoinflammatory disease. Nat Genet. 2016;48(1):67-73.

23. Das T, Chen Z, Hendriks RW, Kool M. A20/Tumor Necrosis Factor $\alpha$-Induced Protein 3 in Immune Cells Controls Development of Autoinflammation and Autoimmunity: Lessons from Mouse Models. Front Immunol. 2018;9:104

24. Sakaguchi S, Sakaguchi N, Asano M, Itoh M, Toda M. Immunologic self-tolerance maintained by activated T cells expressing IL-2 receptor alpha-chains (CD25). Breakdown of a single mechanism of self-tolerance causes various autoimmune diseases. J Immunol. 1995;155(3):1151-1164.

25. Sakaguchi S, et al. Immunologic tolerance maintained by CD25+ CD4+ regulatory T cells: their common role in controlling autoimmunity, tumor immunity, and transplantation tolerance. Immunol Rev. 2001;182:18-32.

26. Montane J, et al. Prevention of murine autoimmune diabetes by CCL22-mediated Treg recruitment to the pancreatic islets. $J$ Clin Invest. 2011;121(8):3024-3028.

27. Mariño E, Villanueva J, Walters S, Liuwantara D, Mackay F, Grey ST. CD4(+)CD25(+) T-cells control autoimmunity in the absence of B-cells. Diabetes. 2009;58(7):1568-1577.

28. Bayer AL, Yu A, Malek TR. Function of the IL-2R for thymic and peripheral CD4+CD25+ Foxp3+ T regulatory cells. $J$ Immunol. 2007;178(7):4062-4071.

29. Setoguchi R, Hori S, Takahashi T, Sakaguchi S. Homeostatic maintenance of natural Foxp3(+) CD25(+) CD4(+) regulatory T cells by interleukin (IL)-2 and induction of autoimmune disease by IL-2 neutralization. J Exp Med. 2005;201(5):723-735.

30. Kopf H, de la Rosa GM, Howard OM, Chen X. Rapamycin inhibits differentiation of Th17 cells and promotes generation of FoxP3+ T regulatory cells. Int Immunopharmacol. 2007;7(13):1819-1824.

31. Zeiser R, et al. Differential impact of mammalian target of rapamycin inhibition on CD4+CD25+Foxp3+ regulatory T cells compared with conventional CD4+ T cells. Blood. 2008;111(1):453-462.

32. Battaglia M, Stabilini A, Migliavacca B, Horejs-Hoeck J, Kaupper T, Roncarolo MG. Rapamycin promotes expansion of functional CD4+CD25+FOXP3 + regulatory $\mathrm{T}$ cells of both healthy subjects and type 1 diabetic patients. J Immunol. 2006;177(12):8338-8347.

33. Battaglia M, Stabilini A, Roncarolo MG. Rapamycin selectively expands CD4+CD25+FoxP3+ regulatory T cells. Blood. 2005;105(12):4743-4748.

34. Zammit NW, et al. Low-dose rapamycin unmasks the protective potential of targeting intragraft NF- $\mathrm{B}$ for islet transplants. Cell Transplant. 2013;22(12):2355-2366

35. Wang JQ, Jeelall YS, Beutler B, Horikawa K, Goodnow CC. Consequences of the recurrent MYD88(L265P) somatic mutation for B cell tolerance. J Exp Med. 2014;211(3):413-426.

36. Zammit NW, et al. Denisovan, modern human and mouse TNFAIP3 alleles tune A20 phosphorylation and immunity. Nat Immunol. 2019;20(10):1299-1310.

37. Rhode A, et al. Islet-specific expression of CXCL10 causes spontaneous islet infiltration and accelerates diabetes development. $J$ Immunol. 2005;175(6):3516-3524.

38. Baker MS, et al. Genetic deletion of chemokine receptor CXCR3 or antibody blockade of its ligand IP-10 modulates posttransplantation graft-site lymphocytic infiltrates and prolongs functional graft survival in pancreatic islet allograft recipients. Surgery. 2003;134(2):126-133.

39. Hancock WW, et al. Requirement of the chemokine receptor CXCR3 for acute allograft rejection. J Exp Med. 2000;192(10):1515-1520.

40. Bach FH, et al. Accommodation of vascularized xenografts: expression of "protective genes" by donor endothelial cells in a host Th2 cytokine environment. Nat Med. 1997;3(2):196-204.

41. Ferran C, Stroka DM, Badrichani AZ, Cooper JT, Bach FH. Adenovirus-mediated gene transfer of A20 renders endothelial cells resistant to activation: a means of evaluating the role of endothelial cell activation in xenograft rejection. Transplant Proc. 1997;29(1-2):879-880.

42. Siracuse JJ, et al. A20-mediated modulation of inflammatory and immune responses in aortic allografts and development of transplant arteriosclerosis. Transplantation. 2012;93(4):373-382.

43. Yang J, Xu MQ, Yan LN, Chen XB, Liu J. Zinc finger protein A20 protects rats against chronic liver allograft dysfunction. World J Gastroenterol. 2012;18(27):3537-3550.

44. Liuwantara D, et al. Nuclear factor-kappaB regulates beta-cell death: a critical role for A20 in beta-cell protection. Diabetes. 2006;55(9):2491-2501

45. Grey ST, Arvelo MB, Hasenkamp W, Bach FH, Ferran C. A20 inhibits cytokine-induced apoptosis and nuclear factor kappaB-dependent gene activation in islets. J Exp Med. 1999;190(8):1135-1146.

46. Zammit NW, Grey ST. Emerging roles for A20 in islet biology and pathology. Adv Exp Med Biol. 2014;809:141-162

47. Wertz IE, et al. Phosphorylation and linear ubiquitin direct A20 inhibition of inflammation. Nature. 2015;528(7582):370-375

48. Grey ST, Arvelo MB, Hasenkamp WM, Bach FH, Ferran C. Adenovirus-mediated gene transfer of the anti-apoptotic protein A20 in rodent islets inhibits IL-1 beta-induced NO release. Transplant Proc. 1999;31(1-2):789.

49. Grey ST, Lock J, Bach FH, Ferran C. Adenovirus-mediated gene transfer of A20 in murine islets inhibits Fas-induced apoptosis. Transplant Proc. 2001;33(1-2):577-578.

50. Grey ST, et al. Genetic engineering of a suboptimal islet graft with A20 preserves beta cell mass and function. J Immunol. 2003;170(12):6250-6256.

51. Ohmori Y, Hamilton TA. The interferon-stimulated response element and a kappa B site mediate synergistic induction of 
murine IP-10 gene transcription by IFN-gamma and TNF-alpha. J Immunol. 1995;154(10):5235-5244.

52. Roep BO, et al. Islet inflammation and CXCL10 in recent-onset type 1 diabetes. Clin Exp Immunol. 2010;159(3):338-343

53. Bender C, et al. Islet-Expressed CXCL10 Promotes Autoimmune Destruction of Islet Isografts in Mice With Type 1 Diabetes. Diabetes. 2017;66(1):113-126.

54. Hancock WW, Gao W, Csizmadia V, Faia KL, Shemmeri N, Luster AD. Donor-derived IP-10 initiates development of acute allograft rejection. J Exp Med. 2001;193(8):975-980.

55. Yoshimatsu G, et al. Pancreatic $\beta$-Cell-Derived IP-10/CXCL10 Isletokine Mediates Early Loss of Graft Function in Islet Cell Transplantation. Diabetes. 2017;66(11):2857-2867.

56. Bettelli E, et al. Reciprocal developmental pathways for the generation of pathogenic effector TH17 and regulatory T cells Nature. 2006;441(7090):235-238.

57. Peng Y, Laouar Y, Li MO, Green EA, Flavell RA. TGF-beta regulates in vivo expansion of Foxp3-expressing CD4+CD25+ regulatory T cells responsible for protection against diabetes. Proc Natl Acad Sci USA. 2004;101(13):4572-4577.

58. Kingsley CI, Karim M, Bushell AR, Wood KJ. CD25+CD4+ regulatory T cells prevent graft rejection: CTLA-4- and IL-10-dependent immunoregulation of alloresponses. J Immunol. 2002;168(3):1080-1086.

59. Hara M, et al. IL-10 is required for regulatory T cells to mediate tolerance to alloantigens in vivo. J Immunol. 2001;166(6):3789-3796.

60. Walters S, et al. Increased CD4+Foxp3+ T cells in BAFF-transgenic mice suppress T cell effector responses. J Immunol. 2009;182(2):793-801.

61. Webster KE, et al. In vivo expansion of $\mathrm{T}$ reg cells with IL-2-mAb complexes: induction of resistance to EAE and long-term acceptance of islet allografts without immunosuppression. J Exp Med. 2009;206(4):751-760.

62. Zheng XX, Sánchez-Fueyo A, Sho M, Domenig C, Sayegh MH, Strom TB. Favorably tipping the balance between cytopathic and regulatory T cells to create transplantation tolerance. Immunity. 2003;19(4):503-514

63. Brinkmann V, Lynch KR. FTY720: targeting G-protein-coupled receptors for sphingosine 1-phosphate in transplantation and autoimmunity. Curr Opin Immunol. 2002;14(5):569-575.

64. Vereecke L, et al. A20 controls intestinal homeostasis through cell-specific activities. Nat Commun. 2014;5:5103.

65. Ma A, Malynn BA. A20: linking a complex regulator of ubiquitylation to immunity and human disease. Nat Rev Immunol. 2012;12(11):774-785

66. Lee EG, et al. Failure to regulate TNF-induced NF-kappaB and cell death responses in A20-deficient mice. Science. 2000;289(5488):2350-2354.

67. Montane J, et al. CCL22 Prevents Rejection of Mouse Islet Allografts and Induces Donor-Specific Tolerance. Cell Transplant. 2015;24(10):2143-2154.

68. Dinarello CA, Simon A, van der Meer JW. Treating inflammation by blocking interleukin-1 in a broad spectrum of diseases. Nat Rev Drug Discov. 2012;11(8):633-652.

69. Miyazaki J, et al. Establishment of a pancreatic beta cell line that retains glucose-inducible insulin secretion: special reference to expression of glucose transporter isoforms. Endocrinology. 1990;127(1):126-132.

70. Ishihara H, et al. Pancreatic beta cell line MIN6 exhibits characteristics of glucose metabolism and glucose-stimulated insulin secretion similar to those of normal islets. Diabetologia. 1993;36(11):1139-1145.

71. Cheng K, et al. High passage MIN6 cells have impaired insulin secretion with impaired glucose and lipid oxidation. PLoS ONE. 2012;7(7):e40868

72. Hanahan D. Heritable formation of pancreatic beta-cell tumours in transgenic mice expressing recombinant insulin/simian virus 40 oncogenes. Nature. 1985;315(6015):115-122.

73. Efrat S, et al. Beta-cell lines derived from transgenic mice expressing a hybrid insulin gene-oncogene. Proc Natl Acad Sci USA. 1988;85(23):9037-9041.

74. Tan BM, et al. Baculoviral inhibitors of apoptosis repeat containing (BIRC) proteins fine-tune TNF-induced nuclear factor $\kappa B$ and c-Jun N-terminal kinase signalling in mouse pancreatic beta cells. Diabetologia. 2013;56(3):520-532.

75. Majumder S, Zhou LZ, Chaturvedi P, Babcock G, Aras S, Ransohoff RM. Regulation of human IP-10 gene expression in astrocytoma cells by inflammatory cytokines. J Neurosci Res. 1998;54(2):169-180.

76. Fox JE, et al. Functional plasticity of the human infant $\beta$-cell exocytotic phenotype. Endocrinology. 2013;154(4):1392-1399.

77. Untergasser A, et al. Primer3--new capabilities and interfaces. Nucleic Acids Res. 2012;40(15):e115.

78. Lyon J, et al. Research-Focused Isolation of Human Islets From Donors With and Without Diabetes at the Alberta Diabetes Institute IsletCore. Endocrinology. 2016;157(2):560-569. 